\title{
Auctions with asymmetric common-values: The first-price format
}

\author{
M.A. de Frutos ${ }^{a, *}$, X. Jarque ${ }^{b}$ \\ ${ }^{a}$ Departamento de Economia, Universidad Carlos III de Madrid, 28903 Getafe, Spain \\ ${ }^{\mathrm{b}}$ Dep. de Mat. Aplicada i Anàlisi, Universitat de Barcelona, Spain
}

\begin{abstract}
We study the performance of the first-price format in auctions with asymmetric common-values. We show that, contrary to the result for second-price auctions, a small advantage for one player translates only to small changes in bidders' strategies, and the equilibrium remains close to the first-price equilibrium of the original game. We characterize the equilibrium bidding strategies and their behavior as the degree of asymmetry increases. Finally, we compare the revenues at the optimal auction, the first-price auction and the second-price auction.
\end{abstract}

JEL classification: D44; D82; T96; G34

Keywords: Common-value auctions; Asymmetric bidders; Spectrum auctions; Optimal auctions

\section{Introduction}

Auction design has been in vogue lately because of the ongoing licensing process for the third generation mobile telephony services (UMTS) throughout Europe. In those auctions several countries established rules to counter potentially deleterious effects created by the presence of asymmetries among bidders. In the valuation of a $3 \mathrm{G}$ license there are common and private components. The common-value arises because profit prospects depend on the development of the UMTS market as a whole, whereas the private value arises because of the economies of scope between the new services and the existing GSM business. Operators already active in GSM services (the incumbents) have an existing infrastructure, a pool of GSM subscribers and

\footnotetext{
* Corresponding author. Tel.: +3491624 9600; fax: +34 916249875.

E-mail addresses: frutos@eco.uc3m.es (M.A. de Frutos), xavier.jarque@ub.edu (X. Jarque).
} 
a database of potential customers which give them a distinct advantage. Also, an incumbent's failure to win a license would adversely impact its existing business. Since incumbents face better initial conditions than newcomers, the private component is asymmetric. ${ }^{1}$

Asymmetries are prevalent in most auctions in practice. They can be due to the presence of a bidder to be known to have a special interest beyond that of others in winning the auction. ${ }^{2}$ They can also be generated by the presence of liquidity constraints. Firms that operate within imperfect capital markets face different costs of raising the amount of cash needed for their bids. Notice that differences in retained earnings, in values of assets appropriate for collateral, or, more generally, in access to external finance, may easily cause asymmetries among bidders. ${ }^{3}$

It is known that small asymmetries can crucially affect who wins, and at what price, in standard ascending auctions for common-value objects. When the auction is conducted as second-price, the bidder who has a disadvantage compared to her opponent (almost surely) never wins. ${ }^{4}$ In equilibrium, the advantageous bidder plays a very aggressive strategy, whereas the disadvantageous plays very conservatively. ${ }^{5}$ The rationale behind this equilibrium behavior is clear. Consider such an auction with two bidders in which they both know that one of them will have for sure a small additional private value whatever common-value is realized, i.e., consider an almost commonvalue auction. Because of the payoff advantage, in an ascending auction the stronger bidder can bid more aggressively, which forces the weaker bidder to bid even more cautiously in order to avoid a loss. The more cautious the behavior of the weaker bidder, the more aggressively the advantageous bidder can bid in this constellation. In equilibrium, the disadvantaged bidder never outbids the advantageous bidder, because she would make a loss in that case. But then a potential competitor with a slightly smaller valuation will see no point in entering the auction. ${ }^{6}$ Moreover, this result holds even if the difference between types becomes negligible, so that the symmetric equilibrium à la Milgrom lies out of the equilibria limit set as one takes a sequence of auctions converging to the symmetric one. ${ }^{7}$

The immediate moral is that a standard ascending auction may not be a good choice in an almost common-value setting as the lack of competition will lower the prices very substantially. An obvious reaction is to recommend using a first-price auction as "the outcome of a sealed-bid auction, in stark contrast to that of an ascending auction, is, it is believed, almost unaffected by small asymmetries among bidders". ${ }^{8}$ But, how does it performs? We show here that the first-price auction gives a disadvantaged bidder a shot at winning. Certainly, an advantageous bidder is more likely to win a first-price auction as well, but the outcome there is much less certain as she cannot

\footnotetext{
${ }^{1}$ Goeree and Offerman (2003) analiyze competitive bidding in auctions with private and common components. In their set-up, bidders are ex-ante symmetric whereas here we are interested in auctions for which bidders are ex-ante asymmetric.

${ }^{2}$ For example in the FCC auctions it was well known that PacTel had a special interest in acquiring licenses in Los Angeles and San Francisco (see Cramton, 1997).

3 In the privatization of ENTel (an argentinean telecommunications company) the winner of the ENTel North (Bell Atlantic and Manufacturers Hanover Corporation) failed to arrange the financing necessary to meet their bid. ENTel North was awarded to the next bidder, a consortium of buyers including France Telecom and J.P. Morgan.

${ }^{4}$ See Bikhchandani (1988); Avery and Kagel (1997); Klemperer (1998), and Bulow and Klemperer (2002) where second-price common-value auctions with asymmetric bidders are analyzed.

5 Nevertheless, the explosive effect reported in the two bidder case does not generalize to the addition of more disadvantageous bidders, as shown in Kagel and Levin (2005).

6 In the U.S. radiospectrum auctions, MCI, the third largest telecommunication company did not participate at all. A similar problem may be behind the low revenue raised by the 2000 Netherlands spectrum auctions.

7 See Bikhchandani (1988) where this result is shown and De Frutos and Pechlivanos (2006) for a discussion about the robustness of the result when one allows for multidimensional uncertainty.

${ }^{8}$ See Bulow and Klemperer (2002; p. 12), where this quotation is taken from.
} 
follow the strategy of bidding very high. Furthermore, the less aggressive bidding by the strong firms reduces the severity of the winner's curse faced by the weak ones, which encourages them to bid more strongly. Contrary to the results for second-price auctions, the first-price almost commonvalue auction has a unique equilibrium (no matter the degree of comparative advantage) which converges uniformly to the symmetric equilibrium of the symmetric auction as the asymmetry vanishes. Hence, the symmetric equilibrium is the equilibrium limit as one takes a sequence of auctions converging to the symmetric one. In this equilibrium a disadvantaged player wins with strictly positive probability unless the asymmetry is so large that gives the advantaged bidder a larger ex-ante valuation than the most optimistic disadvantaged bidder. Consequently, potential competitors with a disadvantage may participate in the auction. ${ }^{9}$

In view of recent debates over the format of government auctions, studying the effects of asymmetries on bidding outcomes is of practical as well as of theoretical importance as asymmetries are the norm and not the exception in many auctions. ${ }^{10}$ We conclude that a first-price auction is a good allocation mechanism in the presence of asymmetries.

The paper is organized as follows. In Section 2 we introduce the model. Section 3 provides the analysis of the first-price auction for the basic model. Section 4 focus on the seller's expected revenue. Section 5 generalizes the results in Section 3 as it is devoted to show the robustness of our results. Finally, Appendix A provides the proofs of two rather technical lemmas.

\section{The model}

Two risk neutral bidders, player A (advantage) and player D (disadvantage), take part in a firstprice auction: one object is auctioned off and given to the player with the highest bid who pays his bid. The value of the object to player $\mathrm{A}$ is $\alpha V$, whereas player D's valuation is $\delta V$ with $\alpha>\delta$ (thus, player $\mathrm{A}$ has a higher ex-post valuation of the object). We will denote an auction in which the values are $\alpha V$ and $\delta V$ by $(\alpha, \delta)$-auction. Throughout the paper we focus on a $(k, 1)$-auction, $k>1$; however, as we go along, we will explain how the results extend easily to any $(\alpha, \delta)$-auction.

For each player $V$ is unknown, but each of them gets a signal ( $x_{\mathrm{A}}$ and $x_{\mathrm{D}}$, respectively) about $V$ before they submit their bids. The players' signals are independent and identically distributed. Without loss of generality, we can normalize so that both signals are uniformly distributed on $[0,1]$. Finally, following Klemperer (1998), players know that the true value of the object is the sum of the signals; i.e., $V=x_{\mathrm{A}}+x_{\mathrm{D}} .^{11}$

This canonical model encompasses different sources of asymmetries:

- It can be used to analyze situations in which the market value of the object is common to all bidders (i.e., they compete for common-value objects), but at the same time, each of them may have an additional private source of gains due to synergies. This could be the case if the object

\footnotetext{
9 This is consistent with the evidence from the 2001 Danish 3G Auction which was conducted as a firts-price sealed-bid auction. It attracted a serious bid from a new entrant and shocked analysts with revenues of $€ 95$ per capita, which almost double most expectations. See Klemperer (2002), and Binmore and Klemperer (2002) for more details.

10 In a recent empirical work, Caputo Silva and Kahn (2001) investigate heterogeneity across different categories of bidders and find evidence that suggests the importance of private components in bidders valuations in Brazilian auctions. The authors conclude that caution should be exercised in studies that assume that treasury auctions are in line with a pure common-values setting.

11 By modelling the common-value in this way, second derivatives with respect to signals vanish, which may be seen as a limitation. In Section 5 we show that our results hold if other, more general, functional forms were considered.
} 
being auctioned off is a target firm in a takeover contest, a state-owned enterprise about to be privatized, or a bankrupted firm under liquidation. The literature refers to these auctions as almost common-value auctions.

- It can also be used for a pure common-value auctions in which bidders differ in their marginal utility of income due to the different financial constraints they may face. ${ }^{12}$ One simple way to model these differences is to consider that bidder A's utility is $\hat{U}_{\mathrm{A}}=V-r_{\mathrm{A}} p$ and bidder D's utility is $\hat{U}_{\mathrm{D}}=V-r_{\mathrm{D}} p$ with $r_{\mathrm{A}}<r_{\mathrm{D}} \cdot{ }^{13}$ Since bidders' utility can be rewritten as

$$
U_{\mathrm{A}}=\frac{V}{r_{\mathrm{A}}}-p=\alpha V-p \quad \text { and } \quad U_{\mathrm{D}}=\frac{V}{r_{\mathrm{D}}}-p=\delta V-p
$$

our set-up allows for this source of asymmetry, too.

\section{Regions}

Consider a $(k, 1)$-auction. This almost common-value auction is equivalent to a common-value auction in which bidders face interest rates given by $r_{\mathrm{A}}=1 / k$ and $r_{\mathrm{D}}=1$. Using this framework, it is easy to see that players' strategic behavior reflect two effects:

- Information effect: players will behave more aggressively the more optimistic is their information, i.e., the larger is their signal.

- Wealth effect: players will behave more aggressively the smaller is the interest rate they face.

The interplay between these two effects will determine the qualitative properties of the equilibrium. In particular, we can distinguish three potential cases by focusing on the impact of these two effects on the bidding behavior of an A player with signal 0, (A-0, for shortness):

Small asymmetries $(1 \leq k<2)$, the information effect dominates and hence player A-0 loses in equilibrium against any type of player D. For these values of $k$, the advantage in terms of wealth is not enough as to compensate the disadvantage coming from the very pessimistic information. Notice that the valuation of player A-0, conditional upon winning over types of player $\mathrm{D}$ below $y$, is smaller than the smallest possible valuation of player D- $y$, i.e., $(k / 2) y<y$ for all $y \in(0,1]$. Intermediate asymmetries $(2 \leq k<3)$, the wealth effect partially dominates the information effect. The valuation of player A-0 conditional upon winning is larger than the valuation of a type of player D with sufficiently pessimistic information. In particular, there will exist a signal $s(k), 0<s(k)<1$, such that, in equilibrium, player A-0 wins over any player D with signal below $s(k)$.

Large asymmetries $(k \geq 3)$, the wealth effect dominates the information effect and hence player $\mathrm{D}$ will never win the auction. ${ }^{14}$ The valuation of player A-0 conditional upon winning is larger than the one of player D-1, i.e., $(k / 2) \geq(1+(1 / 2))$.

\footnotetext{
12 For more on auctions with financially constrained bidders (see Che and Gale, 1998).

${ }^{13}$ In the US spectrum auctions designated firms were given bidding credits (see Ayres and Cramton (1996)). These credits which were intended to offset any disadvantage these firms faced in raising capital (see Cramton, 2001) constitute a good real life example of the existence of different financial constraints.

${ }^{14}$ In the Netherlands UMTS auction, the expected value of a license for the incumbents was estimated in $€ 5$ billions whereas for entrants was estimated in $€ 0.5$ billions. Asymmetries were hence large.
} 
In what follows we analyze the equilibrium bidding strategies in the three possible scenarios. But first, we here state a lemma which guarantees the smoothness of the bidding functions when asymmetries are either small or intermediate.

Lemma 1. If $1 \leq k<3$ holds, then over the common bidding range, bidders' equilibrium strategies are given by continuous and strictly increasing functions, $b_{k}^{\mathrm{A}}\left(x_{\mathrm{A}}\right)$ and $b_{k}^{\mathrm{D}}\left(x_{\mathrm{D}}\right)$, such that $b_{k}^{\mathrm{A}}(1)=b_{k}^{\mathrm{D}}(1)=m(k) \leq 2$. Moreover, if $1 \leq k<2$ then $b_{k}^{\mathrm{A}}(0)=b_{k}^{\mathrm{D}}(0)=0$.

Proof. See Appendix A.

\subsection{Small asymmetries: $1 \leq k<2$}

When differences in values are small, so that the information effect dominates, we will show that there is a unique equilibrium in which bidding strategies, $b_{k}^{\mathrm{A}}\left(x_{\mathrm{A}}\right)$ and $b_{k}^{\mathrm{D}}\left(x_{\mathrm{D}}\right)$, are the solutions to a system of differential equations with boundary conditions $b_{k}^{\mathrm{A}}(0)=b_{k}^{\mathrm{D}}(0)=0$ and $b_{k}^{\mathrm{A}}(1)=$ $b_{k}^{\mathrm{D}}(1)=m(k) \leq 2$, for any $k \in[1,2) .{ }^{15}$

Lemma 1 implies that the bidding functions are two homeomorphisms with continuous and well-defined inverses. Consequently, there exist "equilibrium correspondences", i.e., there exist functions $\phi_{k}^{\mathrm{A}}$ and $\phi_{k}^{\mathrm{D}}$ such that

$$
\begin{gathered}
b_{k}^{\mathrm{A}}\left(\phi_{k}^{\mathrm{A}}\left(x_{\mathrm{D}}\right)\right)=b_{k}^{\mathrm{D}}\left(x_{\mathrm{D}}\right), \\
b_{k}^{\mathrm{D}}\left(\phi_{k}^{\mathrm{D}}\left(x_{\mathrm{A}}\right)\right)=b_{k}^{\mathrm{A}}\left(x_{\mathrm{A}}\right) .
\end{gathered}
$$

Notice that $\phi_{k}^{i}\left(x_{j}\right)=\left(b_{k}^{i}\right)^{-1}\left(b_{k}^{j}\left(x_{j}\right)\right)$ is a continuous and strictly increasing function, with $\phi_{k}^{i}\left(\phi_{k}^{j}\left(x_{i}\right)\right)=x_{i}$, for any $i, j=\mathrm{A}, \mathrm{D}$ with $i \neq j$. Further, $\phi_{k}^{\mathrm{A}}(0)=\phi_{k}^{\mathrm{D}}(0)=0$ and $\phi_{k}^{\mathrm{A}}(1)=\phi_{k}^{\mathrm{D}}(1)=$ 1. The interpretation of this functions is clear. In equilibrium, player A with signal $x_{\mathrm{A}}$ bids the same price than player D with signal $\phi_{k}^{\mathrm{D}}\left(x_{\mathrm{A}}\right)$. Similarly, player D with signal $x_{\mathrm{D}}$ bids the same price than player A with signal $\phi_{k}^{\mathrm{A}}\left(x_{\mathrm{D}}\right)$.

We can hence think of the problem faced by player D as choosing against whom to lose or, equivalently, choosing the opponent signals to beat. ${ }^{16}$ Formally, a player D with signal $x_{\mathrm{D}}$ chooses $x_{\mathrm{A}}$ to maximize her expected utility:

$$
\max _{x_{\mathrm{A}}} \int_{0}^{x_{\mathrm{A}}}\left(x_{\mathrm{D}}+t-b_{k}^{\mathrm{A}}\left(x_{\mathrm{A}}\right)\right) \mathrm{d} t .
$$

Notice that player D's expected utility can be written as

$$
U_{x_{\mathrm{D}}}\left(x_{\mathrm{A}}\right)=x_{\mathrm{D}} x_{\mathrm{A}}+\frac{x_{\mathrm{A}}^{2}}{2}-x_{\mathrm{A}} b_{k}^{\mathrm{A}}\left(x_{\mathrm{A}}\right) .
$$

A sufficient condition for this function to be differentiable is that $x_{\mathrm{A}} b_{k}^{\mathrm{A}}\left(x_{\mathrm{A}}\right)$ be differentiable. ${ }^{17}$

Setting the derivatives of the expected utilities equal to zero, and using the definition of the equilibrium correspondences, we next characterize the equilibrium bid functions.

\footnotetext{
15 Throughout the paper, the subscript in the bidding function denotes the value of $k$, and the superscript denotes the identity of the player, i.e., A or D.

16 A similar approach is taken in Bulow et al. (1999), see also Maskin and Riley (2000).

17 In Appendix A we show the differentiability of the expected utility.
} 
Lemma 2. For any $k \in[1,2)$, the necessary and sufficient conditions for the bidding functions $\left(b_{k}^{\mathrm{A}}, b_{k}^{\mathrm{D}}\right)$ to form a Nash equilibrium are that they are increasing functions solving the differential system

$$
\begin{aligned}
& b_{k}^{\mathrm{A}}\left(x_{\mathrm{A}}\right)+\left(b_{k}^{\mathrm{A}}\right)^{\prime}\left(x_{\mathrm{A}}\right) x_{\mathrm{A}}=\phi_{k}^{\mathrm{D}}\left(x_{\mathrm{A}}\right)+x_{\mathrm{A}} \\
& b_{k}^{\mathrm{D}}\left(x_{\mathrm{D}}\right)+\left(b_{k}^{\mathrm{D}}\right)^{\prime}\left(x_{\mathrm{D}}\right) x_{\mathrm{D}}=k\left(\phi_{k}^{\mathrm{A}}\left(x_{\mathrm{D}}\right)+x_{\mathrm{D}}\right)
\end{aligned}
$$

with boundary conditions: $b_{k}^{\mathrm{A}}(0)=b_{k}^{\mathrm{D}}(0)=0$ and $b_{k}^{\mathrm{A}}(1)=b_{k}^{\mathrm{D}}(1)=m(k)$, where $m(k) \leq 2$.

Since $\phi_{k}^{i}\left(\phi_{k}^{j}\left(x_{i}\right)\right)=x_{i}$ must hold for $i, j=\mathrm{A}, \mathrm{D}$ with $i \neq j$, system above which has two differential equations is, in fact, a system of four differential equations. Notice that by changing variables $\left(x_{\mathrm{A}}\right.$ by $\phi_{k}^{\mathrm{A}}\left(x_{\mathrm{D}}\right)$ in the first equation, and $x_{\mathrm{D}}$ by $\phi_{k}^{\mathrm{D}}\left(x_{\mathrm{A}}\right)$ in the second equation), two "new" equations are obtained. These equations are:

$$
\begin{aligned}
& \left(b_{k}^{\mathrm{D}}\left(x_{\mathrm{D}}\right) \phi_{k}^{\mathrm{A}}\left(x_{\mathrm{D}}\right)\right)^{\prime}=\left(\phi_{k}^{\mathrm{A}}\right)^{\prime}\left(x_{\mathrm{D}}\right)\left(x_{\mathrm{D}}+\phi_{k}^{\mathrm{A}}\left(x_{\mathrm{D}}\right)\right), \\
& \left(b_{k}^{\mathrm{A}}\left(x_{\mathrm{A}}\right) \phi_{k}^{\mathrm{D}}\left(x_{\mathrm{A}}\right)\right)^{\prime}=k\left(\phi_{k}^{\mathrm{D}}\right)^{\prime}\left(x_{\mathrm{A}}\right)\left(x_{\mathrm{A}}+\phi_{k}^{\mathrm{D}}\left(x_{\mathrm{A}}\right)\right) .
\end{aligned}
$$

Integrating (3), we get

$$
\int \phi_{k}^{\mathrm{A}}\left(x_{\mathrm{D}}\right) \mathrm{d} x_{\mathrm{D}}=-b_{k}^{\mathrm{D}}\left(x_{\mathrm{D}}\right) \phi_{k}^{\mathrm{A}}\left(x_{\mathrm{D}}\right)+\phi_{k}^{\mathrm{A}}\left(x_{\mathrm{D}}\right) x_{\mathrm{D}}+\frac{1}{2}\left(\phi_{k}^{\mathrm{A}}\left(x_{\mathrm{D}}\right)\right)^{2}+C_{1} .
$$

Similarly, integrating (4), we get

$$
\int \phi_{k}^{\mathrm{D}}\left(x_{\mathrm{A}}\right) \mathrm{d} x_{\mathrm{A}}=-\frac{1}{k} b_{k}^{\mathrm{A}}\left(x_{\mathrm{A}}\right) \phi_{k}^{\mathrm{D}}\left(x_{\mathrm{A}}\right)+\phi_{k}^{\mathrm{D}}\left(x_{\mathrm{A}}\right) x_{\mathrm{A}}+\frac{1}{2}\left(\phi_{k}^{\mathrm{D}}\left(x_{\mathrm{A}}\right)\right)^{2}+C_{2} .
$$

Using (5) and (6) and the boundary condition $b_{k}^{\mathrm{A}}(0)=b_{k}^{\mathrm{D}}(0)=0$, we can get explicit expressions for the bidding functions after integrating the Eqs. (3) and (4). The resulting bidding functions are:

$$
b_{k}^{\mathrm{A}}\left(x_{\mathrm{A}}\right)=\frac{k}{2} \frac{\left(\phi_{k}^{\mathrm{D}}\left(x_{\mathrm{A}}\right)+x_{\mathrm{A}}\right)^{2}}{\phi_{k}^{\mathrm{D}}\left(x_{\mathrm{A}}\right)+k x_{\mathrm{A}}},
$$

and

$$
b_{k}^{\mathrm{D}}\left(x_{\mathrm{D}}\right)=\frac{k}{2} \frac{\left(x_{\mathrm{D}}+\phi_{k}^{\mathrm{A}}\left(x_{\mathrm{D}}\right)\right)^{2}}{k \phi_{k}^{\mathrm{A}}\left(x_{\mathrm{D}}\right)+x_{\mathrm{D}}} .
$$

The upper boundary condition $b_{k}^{\mathrm{A}}(1)=b_{k}^{\mathrm{D}}(1)=m(k)$ yields $m(k)=2 k /(k+1)$. Hence, the maximum bid is a strictly increasing function in the degree of asymmetry as measured by $k$. Finally, L'Hôpital rule and $\phi_{i}^{\prime}(0)=\left(b_{j}^{\prime}(0) / b_{i}^{\prime}(0)\right)>0$ imply

$$
\lim _{x_{\mathrm{A}} \rightarrow 0} b_{k}^{\mathrm{A}}\left(x_{\mathrm{A}}\right)=\lim _{x_{\mathrm{D}} \rightarrow 0} b_{k}^{\mathrm{D}}\left(x_{\mathrm{D}}\right)=0 .
$$

Using these bidding functions we next characterize the equilibrium correspondences.

Proposition 3. The following statements hold:

(i) If $k=1$, then $\phi_{1}^{\mathrm{A}}\left(x_{\mathrm{A}}\right)=x_{\mathrm{A}}$ and $\phi_{1}^{\mathrm{D}}\left(x_{\mathrm{D}}\right)=x_{\mathrm{D}}$.

(ii) If $k \in(1,2)$, then $\phi_{k}^{\mathrm{A}}\left(x_{\mathrm{D}}\right)$ and $\phi_{k}^{\mathrm{D}}\left(x_{\mathrm{D}}\right)$ are uniquely implicitly defined by the equations

$$
(k+1)^{k-1} x_{\mathrm{D}}^{2 k-1}=\left(\phi_{k}^{\mathrm{A}}\right)^{2-k}\left(k \phi_{k}^{\mathrm{A}}+x_{\mathrm{D}}\right)^{k-1},
$$


and

$$
(k+1)^{k-1}\left(\phi_{k}^{\mathrm{D}}\right)^{2 k-1}=x_{\mathrm{A}}^{2-k}\left(k x_{\mathrm{A}}+\phi_{k}^{\mathrm{D}}\right)^{k-1} .
$$

Proof. We here only show the result for $\phi_{k}^{\mathrm{A}}$. The proof for $\phi_{k}^{\mathrm{D}}$ is completely analogous, and is hence omitted.

By substituting the expression of the bidding function $b_{k}^{\mathrm{D}}\left(x_{\mathrm{D}}\right)$ given in Eq. (8) into (2), we get the differential equation

$$
\left(\phi_{k}^{\mathrm{A}}\right)^{\prime}\left(x_{\mathrm{D}}\right)=\frac{\left(\phi_{k}^{\mathrm{A}}\left(x_{\mathrm{D}}\right)\right)^{2} k(2 k-1)+k x_{\mathrm{D}} \phi_{k}^{\mathrm{A}}\left(x_{\mathrm{D}}\right)}{(2-k) x_{\mathrm{D}}^{2}+k x_{\mathrm{D}} \phi_{k}^{\mathrm{A}}\left(x_{\mathrm{D}}\right)},
$$

which is a homogeneous equation with boundary condition $\phi_{k}^{\mathrm{A}}(1)=1$. The change of variables $u_{k}\left(x_{\mathrm{D}}\right)=\phi_{k}^{\mathrm{A}}\left(x_{\mathrm{D}}\right) / x_{\mathrm{D}}$, yields

$$
\left(u_{k}\right)^{\prime}\left(x_{\mathrm{D}}\right) x_{\mathrm{D}}=u_{k}\left(x_{\mathrm{D}}\right)(2 k-2) \frac{k u_{k}\left(x_{\mathrm{D}}\right)+1}{2-k+k u_{k}\left(x_{\mathrm{D}}\right)},
$$

with boundary condition $u_{k}(1)=1$.

If $k=1$ then $\left(u_{1}\right)^{\prime}\left(x_{\mathrm{D}}\right)=0$ and, consequently, $\phi_{1}^{\mathrm{A}}\left(x_{\mathrm{D}}\right)=x_{\mathrm{D}}$. If $k>1$ then the solution of the differential equation gives

$$
(k+1)^{k-1} x_{\mathrm{D}}^{2 k-1}=\left(\phi_{k}^{\mathrm{A}}\right)^{2-k}\left(k \phi_{k}^{\mathrm{A}}+x_{\mathrm{D}}\right)^{k-1},
$$

as claimed.

To end the proof we now show that implicit equation above has a unique positive solution $\phi_{k}^{\mathrm{A}} \in[0,1]$ for every $x_{\mathrm{D}} \in[0,1]$. To see this, consider by way of contradiction, that there is $x_{\mathrm{D}}=y, y \in(0,1)$, such that both $\phi_{k}^{\mathrm{A}}$ and $\varphi_{k}^{\mathrm{A}}$ are solutions to the implicit equation. Let, w.l.o.g., $0<\phi_{k}^{\mathrm{A}}<\varphi_{k}^{\mathrm{A}}$. Since both of them satisfy the implicit equation, straightforward computations give

$$
\left(\frac{\phi_{k}^{\mathrm{A}}}{\varphi_{k}^{\mathrm{A}}}\right)^{2-k}=\left(\frac{y+k \varphi_{k}^{\mathrm{A}}}{y+k \phi_{k}^{\mathrm{A}}}\right)^{k-1}>1,
$$

a contradiction.

We now proceed to analyze the properties of the equilibrium correspondences. We first present the results and then discuss their implications.

Proposition 4. An advantageous bidder is more likely to win the auction as, $\phi_{k}^{\mathrm{A}}(x)<x<\phi_{k}^{\mathrm{D}}(x)$ holds for all $x \in(0,1)$ and for any $k \in(1,2)$.

Proof. Let $k>1$ be fixed. Assume, by way of contradiction, that there exists $x \in(0,1)$ such that $\phi_{k}^{\mathrm{D}}(x)=x$. For this $x$, implicit Eq. (10) becomes

$$
(k+1)^{k-1} x^{2 k-1}=x^{2-k}(k x+x)^{k-1},
$$

which easily simplifies to $x^{2 k-1}=x$. Since $k>1$ this equality only holds if $x=0$ or $x=1$, a contradiction. The continuity of $\phi_{k}^{\mathrm{D}}(x)$ and $\phi_{k}^{\mathrm{D}}(x) \neq x$ for all $x \in(0,1)$ imply that $\phi_{k}^{\mathrm{D}}$ is either below or above the diagonal. Moreover, as $\phi_{k}^{\mathrm{A}}$ is the inverse function of $\phi_{k}^{\mathrm{D}}$, if one is above the other one is below, and vice-versa. 
Evaluating Eq. (10) at $x=1 / 2$, straightforward computations give:

$$
\left(\phi_{k}^{\mathrm{D}}\left(\frac{1}{2}\right)\right)^{2 k-1}=\frac{1}{2}\left(\frac{k+2 \phi_{k}^{\mathrm{D}}(1 / 2)}{k+1}\right)^{k-1}>\frac{1}{2}\left(\frac{k}{k+1}\right)^{k-1}>\frac{1}{2^{k}} .
$$

Inequality above implies

$$
\phi_{k}^{\mathrm{D}}\left(\frac{1}{2}\right)>\frac{1}{2^{k /(2 k-1)}}>\frac{1}{2} \text {. }
$$

Since $\phi_{k}^{\mathrm{D}}(1 / 2)>1 / 2$, and since there is no $x \in(0,1)$ such that $\phi_{k}^{\mathrm{D}}(x)=x$, we conclude that $\phi_{k}^{\mathrm{A}}(x)<x<\phi_{k}^{\mathrm{D}}(x)$ for all $x \in(0,1)$ and for all $k \in(1,2)$, as claimed.

Proposition 5. For any given $x \in(0,1)$, the equilibrium correspondence functions satisfy

(i) $\phi_{k}^{\mathrm{A}}(x)$ is decreasing in $k$,

(ii) $\phi_{k}^{\mathrm{D}}(x)$ is increasing in $k$,

(iii) $\lim _{k \rightarrow 1^{+}} \phi_{k}^{\mathrm{A}}(x)=\lim _{k \rightarrow 1^{+}} \phi_{k}^{\mathrm{D}}(x)=x$.

Proof. For any pair $k_{1}, k_{2}$ such that $1<k_{1}<k_{2}<2$, incentive compatibility implies that the following inequalities must hold in equilibrium:

$$
\begin{aligned}
& {\left[k_{1}\left(x+\frac{\phi_{k_{1}}^{\mathrm{D}}(x)}{2}\right)-b_{k_{1}}^{\mathrm{A}}(x)\right] \phi_{k_{1}}^{\mathrm{D}}(x) \geq\left[k_{1}\left(x+\frac{\phi_{k_{2}}^{\mathrm{D}}(x)}{2}\right)-b_{k_{2}}^{\mathrm{A}}(x)\right] \phi_{k_{2}}^{\mathrm{D}}(x),} \\
& {\left[k_{2}\left(x+\frac{\phi_{k_{2}}^{\mathrm{D}}(x)}{2}\right)-b_{k_{2}}^{\mathrm{A}}(x)\right] \phi_{k_{2}}^{\mathrm{D}}(x) \geq\left[k_{2}\left(x+\frac{\phi_{k_{1}}^{\mathrm{D}}(x)}{2}\right)-b_{k_{1}}^{\mathrm{A}}(x)\right] \phi_{k_{1}}^{\mathrm{D}}(x) .}
\end{aligned}
$$

Adding up inequalities above gives

$$
\left(k_{2}-k_{1}\right)\left(x+\frac{\phi_{k_{1}}^{\mathrm{D}}(x)}{2}\right) \phi_{k_{1}}^{\mathrm{D}}(x) \leq\left(k_{2}-k_{1}\right)\left(x+\frac{\phi_{k_{2}}^{\mathrm{D}}(x)}{2}\right) \phi_{k_{2}}^{\mathrm{D}}(x) .
$$

Since $k_{2}>k_{1}$, we have $\phi_{k_{1}}^{\mathrm{D}}(x) \leq \phi_{k_{2}}^{\mathrm{D}}(x)$. This result and the inverse relationship between the equilibrium correspondences imply (i) and (ii).

Regarding (iii), if $x=0$ or $x=1$, it hods trivially. We can hence concentrate in the case $x \in(0,1)$. Consider the sequence $\left\{\phi_{k_{n}}^{\mathrm{D}}(x)\right\}$ as $\left\{k_{n}\right\} \rightarrow 1$ (with all $k_{n} \in(1,2)$ ). For any $n$, Eq. (10) yields

$$
\left(\phi_{k_{n}}^{\mathrm{D}}\right)^{2 k_{n}-1}=\left(\frac{k_{n} x+\phi_{k_{n}}^{\mathrm{D}}}{k_{n}+1}\right)^{k_{n}-1} x^{2-k_{n}} .
$$

Moreover, for any $x$ there exists $\epsilon_{x}>0$ such that $\left(k_{n} x+\phi_{k_{n}}^{\mathrm{D}}\right) /\left(k_{n}+1\right)>\epsilon_{x}$ holds for large enough $n$. Consequently,

$$
\left(\frac{k_{n} x+\phi_{k_{n}}^{\mathrm{D}}}{k_{n}+1}\right)^{k_{n}-1} \rightarrow 1, \quad \text { as } n \rightarrow \infty
$$

and statement (iii) follows. Similar arguments apply for $\phi_{k_{n}}^{\mathrm{A}}(x)$ which completes the proof. 
The implications of discussions above and Proposition 5 are several:

- The probabilities of winning the auction are sensitive to the degree of comparative advantage. In particular, the larger is $k$, the more likely is for the advantageous player to win the auction.

- Increasing the comparative advantage (as measured by $k$ ) makes the advantageous player to bid more aggressively. That is $\left(\partial b_{k}^{\mathrm{A}}(x) / \partial k\right)>0$ for all $x>0$. This is what we expect as a higher $k$ makes the A bidder more eager to win. As for the D player, we know that when she has sufficiently optimistic information (in particular when $x_{\mathrm{D}}=1$ ), she bids more aggressively if $k$ is increased. Our conjecture is that the opposite should hold for types of the D bidder with sufficiently pessimistic information. The intuition is that they face a larger winner's curse of winning against a more aggressive A bidder, and this should make them reluctant to increase their bid.

- The profits of the advantageous (disadvantageous) bidder are strictly increasing (decreasing) in $k$. Notice that from the Envelope Theorem we have

$$
\frac{\mathrm{d} \Pi_{k}^{i}}{\mathrm{~d} x_{i}}=\left\{\begin{array}{ll}
k \phi_{k}^{\mathrm{D}}\left(x_{\mathrm{A}}\right), & \text { if } i=\mathrm{A} \\
\phi_{k}^{\mathrm{A}}\left(x_{\mathrm{D}}\right), & \text { if } i=\mathrm{D}
\end{array} .\right.
$$

Hence, $\Pi_{k}^{\mathrm{A}}\left(x_{\mathrm{A}}\right)=\Pi_{k}^{\mathrm{A}}(0)+k \int_{0}^{x_{\mathrm{A}}} \phi_{k}^{\mathrm{D}}(z) \mathrm{d} z$ which is strictly increasing in $k$. Similarly, $\Pi_{k}^{\mathrm{D}}\left(x_{\mathrm{D}}\right)=\Pi_{k}^{\mathrm{D}}(0)+\int_{0}^{x_{\mathrm{D}}} \phi_{k}^{\mathrm{A}}(z) \mathrm{d} z$ which is strictly decreasing in $k$.

- Finally, Proposition 5(iii) suggests that as the auction converges to a symmetric one in which both bidders are known to be D-type, the strategies converge to the unique symmetric equilibrium strategies of the symmetric auction. Next theorem shows that this is indeed the case.

Theorem 6. The unique equilibrium bidding functions $\left(b_{k}^{\mathrm{A}}, b_{k}^{\mathrm{D}}\right)$ of the $(k, 1)$-auction game converge uniformly to the unique equilibrium bidding functions of the (1,1)-auction game as $k$ converges to 1 .

Proof. Pointwise convergence follows trivially from Proposition 5. Because of the functional form of the bidding functions, their uniform convergence to the unique equilibrium bidding functions of the $(1,1)$-auction follow from the uniform convergence of the equilibrium correspondences to the identity map. In what follows we show uniform convergence for $\phi_{k}^{\mathrm{A}}\left(x_{\mathrm{D}}\right)$. The case of $\phi_{k}^{\mathrm{D}}\left(x_{\mathrm{A}}\right)$ follows similarly.

From previous results we know that $\phi_{k}^{\mathrm{A}}\left(x_{\mathrm{D}}\right)$ is a strictly increasing differentiable function such that $\phi_{k}^{\mathrm{A}}(0)=0, \phi_{k}^{\mathrm{A}}(1)=1$ and $\phi_{k}^{\mathrm{A}}\left(x_{\mathrm{D}}\right)>x_{\mathrm{D}}$ for all $x_{\mathrm{D}} \in(0,1)$. Moreover, the derivative is given by

$$
\left(\phi_{k}^{\mathrm{A}}\right)^{\prime}\left(x_{\mathrm{D}}\right)=\frac{\left(\phi_{k}^{\mathrm{A}}\left(x_{\mathrm{D}}\right)\right)^{2} k(2 k-1)+k x_{\mathrm{D}} \phi_{k}^{\mathrm{A}}\left(x_{\mathrm{D}}\right)}{(2-k) x_{\mathrm{D}}^{2}+k x_{\mathrm{D}} \phi_{k}^{\mathrm{A}}\left(x_{\mathrm{D}}\right)} .
$$

We want to show that, given $\varepsilon>0$, there exist $k_{0}$ such that $x_{\mathrm{D}}<\phi_{k}^{\mathrm{A}}\left(x_{\mathrm{D}}\right)<x_{\mathrm{D}}+\varepsilon$ for all $k \geq k_{0}$ and all $x \in[0,1]$. To do so we notice that, for a fixed $k>1$, the equation $\left(\phi_{k}^{\mathrm{A}}\right)^{\prime}\left(x_{\mathrm{D}}\right)=1$ has a unique solution (in $(0,1))$ lying in the straight line

$$
\phi_{k}^{\mathrm{A}}\left(x_{\mathrm{D}}\right)=\sqrt{\frac{2-k}{k(2 k-1)}} x_{\mathrm{D}} .
$$


The slope of this straight line tends to 1 as $k \rightarrow 1$. Let $k_{0}>1$ be the value of $k$ such that the above straight line is totally contained between $y=x_{\mathrm{D}}$ and $y=x_{\mathrm{D}}+\epsilon$. The Mean Value Theorem, and the fact that $\phi_{k}^{\mathrm{A}}(\cdot)$ is a decreasing function of $k$, implies that for all $k \geq k_{0}$ we have $x_{\mathrm{D}}<\phi_{k}^{\mathrm{A}}\left(x_{\mathrm{D}}\right)<$ $x_{\mathrm{D}}+\varepsilon$, as desired.

\subsection{Intermediate asymmetries: $2 \leq k<3$}

As the difference in values increase, the information effect no longer dominates and hence players A-0 and D-0 behave differently in the auction. In particular, player A-0 must win the auction with positive probability. In this scenario, there will exist a signal $s(k)>0$ for the disadvantageous bidder such that $b_{k}^{\mathrm{A}}(0)=b_{k}^{\mathrm{D}}(s(k))=\alpha(k)>0$. Further, the only possible atoms in the bidding functions occur at the bottom of the common bidding prices, as shown in Lemma 1. Consequently, let us define $r(k)$ as the highest $x_{\mathrm{A}}$ that satisfies $b_{k}^{\mathrm{A}}(r(k))=b_{k}^{\mathrm{D}}(s(k))$. Notice that $r(k)=0$ is not ruled out a priory. Finally, $b_{k}^{\mathrm{A}}(1)=b_{k}^{\mathrm{D}}(1)=m(k)<2$ must also hold in any equilibrium candidate.

Lemma 7. For any $k \in[2,3)$, in equilibrium bidders $\mathrm{A}-0$ and $\mathrm{D}-s(k)$ must break even.

Proof. Clearly, D-s $(k)$ cannot make negative profits or she would be better off by reducing her bid so as to lose with probability one. But she cannot make positive profits either. Otherwise, a D player with signal $s(k)-\varepsilon$ would have incentives to raise her bid, a contradiction with equilibrium behavior.

The result for the A-0 bidder follows from the definition of $s(k)$. Since conditional upon winning bidder A-0 and bidder D-s( $k)$ assign the same value to the object, it follows that $k s(k) / 2=s(k)+$ $r(k) / 2$. Consequently, $\Pi_{k}^{\mathrm{A}}\left(x_{\mathrm{A}}\right)=s(k)\left(k s(k) / 2-b_{k}^{\mathrm{A}}(0)\right)$ equals zero as $b_{k}^{\mathrm{A}}(0)=b_{k}^{\mathrm{D}}(s(k))$.

Corollary 8. For $k \in[2,3)$ we have

(i) $\alpha(k)=\frac{k s(k)}{2}$;

(ii) $r(k)=(k-2) s(k)$.

The equilibrium bidding strategies of players with signals $x_{\mathrm{A}}>r(k)$ and $x_{\mathrm{D}}>s(k)$, are increasing differentiable functions, which are solutions of the system given by Eqs. (3) and (4) with boundary conditions $b_{k}^{\mathrm{A}}((k-2) s(k))=b_{k}^{\mathrm{D}}(s(k))=k s(k) / 2$ and $b_{k}^{\mathrm{A}}(1)=b_{k}^{\mathrm{D}}(1)=m(k)$. Integrating, and using the boundary conditions, we get explicit expressions for the truncated bidding functions $\left(b_{k}^{\mathrm{A}}, b_{k}^{\mathrm{D}}\right)$ in terms of the equilibrium correspondences. Moreover, Lemma 7 and Corollary 8 allow us to fully characterize the equilibrium bidding functions. Let

$$
b_{k}^{\mathrm{A}}\left(x_{\mathrm{A}}\right)=\left\{\begin{array}{ll}
\frac{k s(k)}{2}, & \text { if } 0 \leq x_{\mathrm{A}}<r(k) \\
\frac{k}{2} \frac{\left(x_{\mathrm{A}}+\phi_{k}^{\mathrm{D}}\left(x_{\mathrm{A}}\right)\right)^{2}}{\phi_{k}^{\mathrm{D}}\left(x_{\mathrm{A}}\right)+k x_{\mathrm{A}}}, & \text { if } r(k) \leq x_{\mathrm{A}} \leq 1
\end{array},\right.
$$

and

$$
b_{k}^{\mathrm{D}}\left(x_{\mathrm{D}}\right)=\left\{\begin{array}{ll}
x_{\mathrm{D}}+\frac{r(k)}{2}, & \text { if } 0 \leq x_{\mathrm{D}}<s(k) \\
\frac{k}{2} \frac{\left(x_{\mathrm{D}}+\phi_{k}^{\mathrm{A}}\left(x_{\mathrm{D}}\right)\right)^{2}}{k \phi_{k}^{\mathrm{A}}\left(x_{\mathrm{D}}\right)+x_{\mathrm{D}}}, & \text { if } s(k) \leq x_{\mathrm{D}} \leq 1
\end{array} .\right.
$$


In what follows, we show that $b_{k}^{\mathrm{A}}\left(x_{\mathrm{A}}\right)$ given by (12) and $b_{k}^{\mathrm{D}}\left(x_{\mathrm{D}}\right)$ given by (13) are equilibrium bidding strategies.

Proposition 9. The bidding functions $\left(b_{k}^{\mathrm{A}}\left(x_{\mathrm{A}}\right), b_{k}^{\mathrm{D}}\left(x_{\mathrm{D}}\right)\right)$, given by (12) and (13), constitute an equilibrium of the $(k, 1)$-auction for any $k \in[2,3)$. Furthermore,

$$
s(k)=(k-2)^{(k-2) / 2(k-1)} \frac{k-1}{(k+1)^{1 / 2}}
$$

Proof. Clearly a D player with signal below $s(k)$ does not want to deviate up so as to win over some types of player A. Just notice that the minimum bid is larger than her value conditional upon winning. Similarly, a D player with signal larger than $s(k)$ plays a best response against the strategy of the A player. There is hence no profitable deviation for the $\mathrm{D}$ player. Consider now the A player. If her signal is $y$ and it is below $r(k)$, her expected profit when playing the equilibrium strategy is

$$
\Pi^{\mathrm{A}-y}\left(b_{k}^{\mathrm{A}}(y), b_{k}^{\mathrm{D}}\left(x_{\mathrm{D}}\right)\right)=k y s(k) \geq 0, \quad \text { for all } y \in[0, r(k)] .
$$

Since the A player with signal $r(k)$ does not want to deviate up (recall that the truncated bidding functions are best reply to each other), then no other type with worse information will want to deviate either. Thus the only deviation we have to consider is a deviation to a bid below $k s(k) / 2$. Let $\beta$ be such that $\beta<(k s(k) / 2)$. For any $y, y \in[0, r(k)]$, the expected profit when bidding $\beta$ is

$$
\Pi^{\mathrm{A}-y}\left(\beta, b_{k}^{\mathrm{D}}\left(x_{\mathrm{D}}\right)\right)=\left[k\left(y+\frac{2 \beta-r(k)}{4}\right)-\beta\right]\left(\frac{2 \beta-r(k)}{2}\right) .
$$

The probability of winning is now smaller but, further, the profit when winning is also smaller. Notice that

$$
k\left(\frac{2 \beta-r(k)}{4}\right)-\beta \leq 0, \quad \text { as } 2 \beta(k-2) \leq k(k-2) s(k) .
$$

We hence conclude that no deviation down is profitable as

$$
\Pi^{\mathrm{A}-y}\left(b_{k}^{\mathrm{A}}(y), b_{k}^{\mathrm{D}}\left(x_{\mathrm{D}}\right)\right) \geq \Pi^{\mathrm{A}-y}\left(\beta, b_{k}^{\mathrm{D}}\left(x_{\mathrm{D}}\right)\right), \quad \text { for all } \beta<\frac{k s(k)}{2} \text { and all } y \leq r(k) .
$$

Finally, the A player with signal larger than $r(k)$ plays a best response against the strategy of the D player. So the purported strategies constitute an equilibrium. Since over the common bidding range, the functional forms of the equilibrium bidding functions coincide with the ones obtained for small asymmetries, the equilibrium correspondences $\phi_{k}^{\mathrm{A}}\left(x_{\mathrm{D}}\right)$ and $\phi_{k}^{\mathrm{D}}\left(x_{\mathrm{A}}\right)$ are (uniquely) defined by the Eqs. (9) and (10). Using those equations we can fully characterize the minimum winning bid. In particular, straightforward computations yield:

$$
s(k)=(k-2)^{-((k-2) / 2(k-1))} \frac{(k-1)}{(k+1)^{1 / 2}} .
$$

Notice that $\lim _{k \rightarrow 2} s(k)=(1 / 3) \sqrt{3}$ and $s(3)=1$. Consequently, $\lim _{k \rightarrow 2} \alpha(k)=(1 / 3) \sqrt{3}$ and $\alpha(3)=3 / 2$. These results suggest that as $k$ converges to 3 the probability of winning the auction for the D player converges to zero. Next subsection shows that this is indeed the case. 


\subsection{Large asymmetries: $k \geq 3$}

When the asymmetry in values is such that the A-0 player can assign to the object a larger ex-ante expected value than the most optimistic D player (i.e., when $k / 2 \geq 3 / 2$ ) then, in any equilibrium, the A player must win the auction.

Proposition 10. The following strategies constitute an equilibrium of the (k, 1)-auction game for any $k \geq 3$,

$$
\begin{aligned}
& b_{k}^{\mathrm{A}}\left(x_{\mathrm{A}}\right)=\frac{3}{2} ; \\
& b_{k}^{\mathrm{D}}\left(x_{\mathrm{D}}\right)=x_{\mathrm{D}}+\frac{1}{2} .
\end{aligned}
$$

Proof. We first show that no type of player $\mathrm{D}$ wants to deviate. At the purported equilibrium strategies player D gets zero profits. By deviating and bidding more than $3 / 2$, she gets negative profits as she would pay more than the true value conditional on her winning. Notice that, conditional on winning, the value is bounded above by $3 / 2$ for any $\mathrm{D}$ player.

Consider now the A player. We now show that type 0 prefers to outbid all types of player $\mathrm{D}$ rather than a set of them. At the purported equilibrium the profits of type 0 are:

$$
\Pi^{\mathrm{A}-0}\left(\frac{3}{2}, b_{k}^{\mathrm{D}}\left(x_{\mathrm{D}}\right)\right)=\frac{k}{2}-\frac{3}{2}
$$

Consider now a bid equal to $m$ such that $1 / 2 \leq m<3 / 2$. She wins over all types of D smaller than $y$ where $y$ is such that $y+1 / 2=m$. Her expected profits from bidding $m$ are

$$
\Pi^{\mathrm{A}-0}\left(m, b_{k}^{\mathrm{D}}\left(x_{\mathrm{D}}\right)\right)=\left(k \frac{2 m-1}{4}-m\right) \frac{2 m-1}{2}
$$

Since her probability of winning with a bid equal to $m$ is below one, we have

$$
\Pi^{\mathrm{A}-0}\left(m, b_{k}^{\mathrm{D}}\left(x_{\mathrm{D}}\right)\right)<k \frac{2 m-1}{4}-m \leq \frac{k-3}{2}, \quad \text { for all } k \geq 3 .
$$

Hence $\Pi^{A-0}\left(m, b_{k}^{\mathrm{D}}\left(x_{\mathrm{D}}\right)\right)<\Pi^{A-0}\left(3 / 2, b_{k}^{\mathrm{D}}\left(x_{\mathrm{D}}\right)\right)$. If type 0 does not find profitable to deviate, then no other type will have incentives to deviate either, which completes the proof.

Equilibrium above is qualitatively unique as in any equilibrium for $k \geq 3$, the advantageous bidder always bids $3 / 2$ and the disadvantageous (almost) never wins. ${ }^{18}$

Fig. 1 illustrates the behavior of the equilibrium bidding functions in the three possible scenarios.

\section{4. $(\alpha, \delta)$-Auctions}

To end this section we now show how our results generalize to any $(\alpha, \delta)$-auction, $\alpha>\delta>0$. In particular, we now show that a $(\alpha, \delta)$-auction is strategically equivalent to a $(\alpha / \delta, 1)$-auction, which ensures that there is no loss of generality by focusing on $(k, 1)$-auctions.

\footnotetext{
${ }^{18}$ Nevertheless, there is a family of equilibrium bids for the D player. In particular, $b_{k}^{\mathrm{D}}\left(x_{\mathrm{D}}\right)=\rho+(3 / 2-\rho) x_{\mathrm{D}}$ is an equilibrium bid for any $\rho \in[0,1 / 2]$.
} 

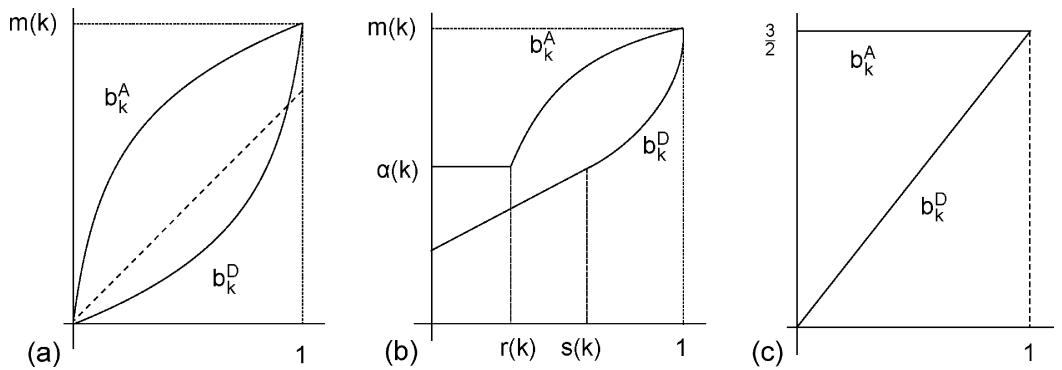

Fig. 1. Equilibrium bidding functions in the three possible scenarios: (a) $k \in(1,2)$, (b) $k \in[2,3$ ), and (c) $k>3$.

Throughout this subsection, $b_{\alpha, \delta}^{i}$ stands for player $i$ 's equilibrium bidding function in a $(\alpha, \delta)$ auction. In particular, for the sake of consistency, we will here write $b_{k, 1}^{i}$ to refer to player $i$ 's equilibrium bidding function in a $(k, 1)$-auction.

Lemma 11. The equilibrium bidding functions of $a(\alpha, \delta)$-auction are given by $b_{\alpha, \delta}^{\mathrm{A}}\left(x_{\mathrm{A}}\right)=$ $\delta b_{k, 1}^{\mathrm{A}}\left(x_{\mathrm{A}}\right)$ and $b_{\alpha, \delta}^{\mathrm{D}}\left(x_{\mathrm{D}}\right)=\delta b_{k, 1}^{\mathrm{D}}\left(x_{\mathrm{D}}\right)$ for $k=\alpha / \delta$.

Proof. Two cases have to be considered depending on whether $\alpha / \delta \geq 3$ or $\alpha / \delta<3$.

If $\alpha / \delta \geq 3$, similar arguments to the ones used in the proof of Proposition 10 ensure that

$$
\begin{aligned}
& b_{\alpha, \delta}^{\mathrm{A}}\left(x_{\mathrm{A}}\right)=\delta \frac{3}{2}, \\
& b_{\alpha, \delta}^{\mathrm{D}}\left(x_{\mathrm{D}}\right)=\delta\left(x_{\mathrm{D}}+\frac{1}{2}\right) .
\end{aligned}
$$

constitute an equilibrium of the $(\alpha, \delta)$-auction game.

If $\alpha / \delta<3$, the equilibrium bidding functions over the common range of bidding prices have to be increasing functions solving the system of differential equations

$$
\begin{aligned}
& \left(x_{\mathrm{A}} b_{\alpha, \delta}^{\mathrm{A}}\left(x_{\mathrm{A}}\right)\right)^{\prime}=\delta\left(\phi_{\alpha, \delta}^{\mathrm{D}}\left(x_{\mathrm{A}}\right)+x_{\mathrm{A}}\right) \\
& \left(x_{\mathrm{D}} b_{\alpha, \delta}^{\mathrm{D}}\left(x_{\mathrm{D}}\right)\right)^{\prime}=\alpha\left(\phi_{\alpha, \delta}^{\mathrm{A}}\left(x_{\mathrm{D}}\right)+x_{\mathrm{D}}\right)
\end{aligned}
$$

where $\phi_{\alpha, \delta}^{\mathrm{A}}\left(x_{\mathrm{D}}\right)$ and $\phi_{\alpha, \delta}^{\mathrm{D}}\left(x_{\mathrm{A}}\right)$ are the equilibrium correspondences of the $(\alpha, \delta)$-auction game. Since $b_{\alpha / \delta, 1}^{\mathrm{A}}\left(x_{\mathrm{A}}\right)$ and $b_{\alpha / \delta, 1}^{\mathrm{D}}\left(x_{\mathrm{D}}\right)$ solve the system given by Eqs. (3) and (4), then it is easily verified that $b_{\alpha, \delta}^{\mathrm{A}}\left(x_{\mathrm{A}}\right)=\delta b_{\alpha / \delta, 1}^{\mathrm{A}}\left(x_{\mathrm{A}}\right)$ and $b_{\alpha, \delta}^{\mathrm{D}}\left(x_{\mathrm{D}}\right)=\delta b_{\alpha / \delta, 1}^{\mathrm{D}}\left(x_{\mathrm{D}}\right)$ solve system $(14)$, as claimed.

\section{Expected revenue}

Expected revenue to the seller is the sum of the ex-ante expected payments by the players. For player $i$ with signal $x_{i}$, her interim expected payment will be $b_{k}^{i}\left(x_{i}\right) \phi k\left(x_{i}\right), i, j=\mathrm{A}, \mathrm{D}$. For the advantaged player it increases with $k$ as both her bid and her probability of winning are increasing functions of $k$. For the disadvantaged player her expected payment will be (most likely) decreasing in $k$ for sufficiently pessimistic information. Nevertheless, for the most optimistic D player the opposite holds as her bid increases with $k$ whereas her probability of winning is always one. The impact of $k$ on the expected revenue is hence unclear a priory. 
To compute the expected revenue we first note that integrating by parts Eq. (3) results in

$$
\begin{aligned}
b_{k}^{\mathrm{A}}\left(x_{\mathrm{A}}\right) \phi_{k}^{\mathrm{D}}\left(x_{\mathrm{A}}\right) & =k \int_{0}^{x_{\mathrm{A}}}\left(\phi_{k}^{\mathrm{D}}(t)\right)^{\prime}\left(\phi_{k}^{\mathrm{D}}(t)+t\right) \mathrm{d} t \\
& =k\left(\frac{1}{2}\left(\phi_{k}^{\mathrm{D}}\left(x_{\mathrm{A}}\right)\right)^{2}+x_{\mathrm{A}} \phi_{k}^{\mathrm{D}}\left(x_{\mathrm{A}}\right)-\int_{0}^{x_{\mathrm{A}}} \phi_{k}^{\mathrm{D}}(t) \mathrm{d} t\right),
\end{aligned}
$$

which implies

$$
\int_{0}^{1} b_{k}^{\mathrm{A}}(x) \phi_{k}^{\mathrm{D}}(x) \mathrm{d} x=k \int_{0}^{1}\left[\frac{1}{2}\left(\phi_{k}^{\mathrm{D}}(x)\right)^{2}+2 x \phi_{k}^{\mathrm{D}}(x)\right] \mathrm{d} x-\frac{k(3 k-1)}{2(k+1)},
$$

where, $\int_{0}^{1} \phi_{k}^{\mathrm{D}}(x) \mathrm{d} x=((3 k-1) / 2(k+1))$ is derived from Eq. (6). Similarly,

$$
\int_{0}^{1} b_{k}^{\mathrm{D}}(x) \phi_{k}^{\mathrm{A}}(x) \mathrm{d} x=\int_{0}^{1}\left[\frac{1}{2}\left(\phi_{k}^{\mathrm{A}}(x)\right)^{2}+2 x \phi_{k}^{\mathrm{A}}(x)\right] \mathrm{d} x-\frac{(3-k)}{2(k+1)} .
$$

Changing variables in (15), take $x=\phi_{k}^{\mathrm{A}}(t)$, revenue to the seller becomes

$$
R_{k}^{\mathrm{S}}=\frac{5 k-3}{2(k+1)}-\int_{0}^{1}\left((2 k-1)\left(\frac{\left(\phi_{k}^{\mathrm{A}}\left(x_{\mathrm{D}}\right)\right)^{2}}{2}\right)-(2-k) x_{\mathrm{D}} \phi_{k}^{\mathrm{A}}\left(x_{\mathrm{D}}\right)\right) \mathrm{d} x_{\mathrm{D}}
$$

Bikhchandani (1988) and Klemperer (1998) have shown that second-price auctions are considerably less desirable for the seller in asymmetric environments than in symmetric ones. They showed that a small asymmetry in values has a large impact on the seller's expected revenues. We have shown here that a small asymmetry in values has only a small impact on outcomes when the auction is conducted as a first-price auction. But, further, we now show that it is beneficial for the seller.

Proposition 12. A small asymmetry in values is beneficial for the seller.

Proof. Differentiating Eq. (16) with respect to $k$ gives

$$
\begin{aligned}
\frac{\partial R_{k}}{\partial k}= & 4(k+1)^{-2}-\int_{0}^{1}\left(\phi_{k}^{\mathrm{A}}(t)\right)^{2} \mathrm{~d} t-\int_{0}^{1} t \phi_{k}^{\mathrm{A}}(t) \mathrm{d} t+-(2 k-1) \int_{0}^{1} \phi_{k}^{\mathrm{A}}(t) \frac{\partial \phi_{k}^{\mathrm{A}}(t)}{\partial k} \mathrm{~d} t \\
& +(2-k) \int_{0}^{1} t \frac{\partial \phi_{k}^{\mathrm{A}}(t)}{\partial k} \mathrm{~d} t
\end{aligned}
$$

Using the fact that $\phi_{k}^{\mathrm{A}}(x)=x$ for $k=1$ and for all $x \in[0,1]$, it is easily verified that $\left(\partial R_{k}^{\mathrm{S}} /\left.\partial k\right|_{k=1}\right)=(1 / 3)>0 .{ }^{19}$ Hence a small asymmetry ( $k$ close enough to one) is beneficial for the seller.

From the proof of proposition above it is easy to see that the expected revenue is also increasing at $k=2$. If this were always the case when there are asymmetries, it would imply that in the firstprice auction the seller benefits from the asymmetry among bidders. To examine this issue and to illustrate how the degree of comparative advantage translates into payments, we now provide the seller's revenue for some values of $k$. The choice of these values is not arbitrary. We have taken

\footnotetext{
${ }^{19}$ Formally, we here provide the right derivative.
} 
those for which $\phi_{k}^{\mathrm{A}}\left(x_{\mathrm{D}}\right)$ can be explicitly determined. In particular, straightforward integration gives

\begin{tabular}{llll}
\hline$\phi_{1}^{\mathrm{A}}\left(x_{\mathrm{D}}\right)=x_{\mathrm{D}}$ & $\phi_{1.5}^{\mathrm{A}}\left(x_{\mathrm{D}}\right)=\frac{x_{\mathrm{D}}\left(\sqrt{1+15 x_{\mathrm{D}}^{2}}-1\right)}{3}$ & $\phi_{2}^{\mathrm{A}}\left(x_{\mathrm{D}}\right)=\frac{x_{\mathrm{D}}\left(3 x_{\mathrm{D}}^{2}-1\right)}{2}$ & $\phi_{3}^{\mathrm{A}}\left(x_{\mathrm{D}}\right)=0$ \\
$R_{1}=\frac{2}{3}=0.666$ & $R_{1.5}=0.837$ & $R_{2}=0.967$ & $R_{3}=1.5$ \\
\hline
\end{tabular}

Table above suggests that the seller's revenue increases with the degree of comparative advantage, and that significant asymmetries $(k \geq 2)$ translate into large rents. The economic intuition behind this fact follows from two effects. On one hand, an increase in $k$ makes the object more valuable for the advantageous bidder who is then more willing to bid higher in order to ensure her winning. On the other hand, an increase in $k$ aggravates the situation of the disadvantageous player who must now make an extra effort to win the auction. In particular, if she has sufficiently optimistic information about the common-value (her signal is sufficiently high), she is force to bid higher the greater is her disadvantage. Since both effect are aligned, the impact of a larger asymmetry is a larger payment and hence a larger seller's revenue.

To better asses the performance of the first-price format, in what follows we characterize the optimal auction to compare the seller's expected revenue in the first-price auction with the optimal auction and with the second-price auction.

\subsection{The optimal auction}

From the revelation principle we can restrict attention to direct mechanisms. Denote by $m_{k}^{i}\left(x_{i}, x_{j}\right)$ the payment from $i$ to the auctioneer when reported signals are $x_{i}$ and $x_{j}$, and by $p_{k}^{i}\left(x_{i}, x_{j}\right)$ the probability that $i$ gets the asset. Conditional on signal $x_{i}$ and announcement $\hat{x}_{i}$, bidder $i$ 's expected payoff is

$$
U_{k}^{i}\left(\hat{x}_{i} / x_{i}\right)=\left\{\begin{array}{ll}
\int_{0}^{1}\left(k v\left(x_{i}, x_{j}\right) p_{k}^{i}\left(\hat{x}_{i}, x_{j}\right)-m_{k}^{i}\left(\hat{x}_{i}, x_{j}\right)\right) f\left(x_{j}\right) \mathrm{d} x_{j}, & \text { if } i=\mathrm{A} \\
\int_{0}^{1}\left(v\left(x_{i}, x_{j}\right) p_{k}^{i}\left(\hat{x}_{i}, x_{j}\right)-m_{k}^{i}\left(\hat{x}_{i}, x_{j}\right)\right) f\left(x_{j}\right) \mathrm{d} x_{j}, & \text { if } i=\mathrm{D}
\end{array},\right.
$$

and his truthtelling payoff is $\Pi_{k}^{i}\left(x_{i}\right) \equiv U_{k}^{i}\left(x_{i} / x_{i}\right)$.

The optimal auction solves the following problem

$$
\begin{array}{ll}
\max _{m_{k}^{\mathrm{A}}, m_{k}^{\mathrm{D}} \in R, p_{k}^{\mathrm{A}}, p_{k}^{\mathrm{D}} \in[0,1]} \int_{0}^{1} \int_{0}^{1}\left(m_{k}^{\mathrm{A}}\left(x_{\mathrm{A}}, x_{\mathrm{D}}\right)+m_{k}^{\mathrm{D}}\left(x_{\mathrm{A}}, x_{\mathrm{D}}\right)\right) f\left(x_{\mathrm{A}}\right) \mathrm{d} x_{\mathrm{A}} f\left(x_{\mathrm{D}}\right) \mathrm{d} x_{\mathrm{D}} \\
\text { s.t. } \quad \Pi_{k}^{i}\left(x_{i}\right) \geq 0, \quad \text { for all } x_{i}, i=1,2 \\
& \Pi_{k}^{i}\left(x_{i}\right) \geq U_{k}^{i}\left(\hat{x}_{i} / x_{i}\right), \quad \text { for all } x_{i}, \hat{x}_{i}, i=1,2,
\end{array}
$$

and such that the probabilities satisfy standard feasibility conditions, $p_{k}^{i} \in[0,1]$ and $p_{k}^{i}+p_{k}^{j} \leq$ 1. The optimal auction maximizes the seller's expected revenue subject to the constraints of individual rationality, incentive compatibility and feasibility.

Using the Envelope Theorem and applying standard techniques adapted from Myerson (1981), we have

$$
\frac{\mathrm{d} \Pi_{k}^{i}}{\mathrm{~d} x_{i}}=\left\{\begin{array}{ll}
k Q_{k}^{\mathrm{A}}\left(x_{\mathrm{A}}\right), & \text { if } i=\mathrm{A} \\
Q_{k}^{\mathrm{D}}\left(x_{\mathrm{D}}\right), & \text { if } i=\mathrm{D}
\end{array} .\right.
$$


and

$$
\Pi_{k}^{i}\left(x_{i}\right)=\left\{\begin{array}{ll}
\Pi_{k}^{\mathrm{A}}(0)+k \int_{0}^{x_{\mathrm{A}}} Q_{k}^{\mathrm{A}}(z) \mathrm{d} z, & \text { if } i=\mathrm{A} \\
\Pi_{k}^{\mathrm{D}}(0)+\int_{0}^{x_{\mathrm{D}}} Q_{k}^{\mathrm{D}}(z) \mathrm{d} z, & \text { if } i=\mathrm{D}
\end{array},\right.
$$

where $Q_{k}^{i}\left(x_{i}\right)$ stands for bidder $i$ 's probability of winning when his signal is $x_{i}$. Since $Q_{k}^{i}\left(x_{i}\right)=$ $\int_{0}^{1} p_{k}^{i}\left(x_{i}, x_{j}\right) \mathrm{d} x_{j}$, we can rewrite ex-ante profits as

$$
\Pi_{k}^{i}= \begin{cases}\Pi_{k}^{\mathrm{A}}(0)+k \int_{0}^{1} \int_{0}^{1}\left(1-x_{\mathrm{A}}\right) p_{k}^{\mathrm{A}}\left(x_{\mathrm{A}}, x_{\mathrm{D}}\right) \mathrm{d} x_{\mathrm{A}} \mathrm{d} x_{\mathrm{D}}, & \text { if } i=\mathrm{A} \\ \Pi_{k}^{\mathrm{D}}(0)+\int_{0}^{1} \int_{0}^{1}\left(1-x_{\mathrm{D}}\right) p_{k}^{\mathrm{D}}\left(x_{\mathrm{A}}, x_{\mathrm{D}}\right) \mathrm{d} x_{\mathrm{D}} \mathrm{d} x_{\mathrm{A}}, & \text { if } i=\mathrm{D} .\end{cases}
$$

As expected profits are expected values minus expected payments, the optimal auction solves the problem

$$
\begin{aligned}
& \max _{\Pi_{k}^{i}(0), p_{k}^{i}}-\Pi_{k}^{\mathrm{A}}(0)-\Pi_{k}^{\mathrm{D}}(0)+\int_{0}^{1} \int_{0}^{1} k\left(v\left(x_{\mathrm{A}}, x_{\mathrm{D}}\right)-\left(1-x_{\mathrm{A}}\right)\right) p_{k}^{\mathrm{A}}\left(x_{\mathrm{A}}, x_{\mathrm{D}}\right) \mathrm{d} x_{\mathrm{A}} \mathrm{d} x_{\mathrm{D}} \\
& \quad+\int_{0}^{1} \int_{0}^{1}\left(v\left(x_{\mathrm{A}}, x_{\mathrm{D}}\right)-\left(1-x_{\mathrm{D}}\right)\right) p_{k}^{\mathrm{D}}\left(x_{\mathrm{A}}, x_{\mathrm{D}}\right) \mathrm{d} x_{\mathrm{D}} \mathrm{d} x_{\mathrm{A}},
\end{aligned}
$$

where $k\left(v\left(x_{\mathrm{A}}, x_{\mathrm{D}}\right)-\left(1-x_{\mathrm{A}}\right)\right)=k\left(2 x_{\mathrm{A}}+x_{\mathrm{D}}-1\right)$ is the marginal revenue of bidder $\mathrm{A}$, and $v\left(x_{\mathrm{A}}, x_{\mathrm{D}}\right)-\left(1-x_{\mathrm{D}}\right)=x_{\mathrm{A}}+2 x_{\mathrm{D}}-1$ is the marginal revenue of bidder $\mathrm{D}$.

Lemma 13. The optimal auction sets

(i) $\Pi_{k}^{\mathrm{A}}(0)=\Pi_{k}^{\mathrm{D}}(0)=0$,

(ii) $p_{k}^{\mathrm{A}}\left(x_{\mathrm{A}}, x_{\mathrm{D}}\right)=\left\{\begin{array}{ll}1, & \text { if } x_{\mathrm{A}} \geq \frac{1-x_{\mathrm{D}}}{2} \\ 0, & \text { otherwise. }\end{array}\right.$ and $\quad x_{\mathrm{A}} \geq \frac{(2-k) x_{\mathrm{D}}+k-1}{2 k-1} ;$

(iii) $p_{k}^{\mathrm{D}}\left(x_{\mathrm{A}}, x_{\mathrm{D}}\right)= \begin{cases}1, & \text { if } x_{\mathrm{D}} \geq \frac{1-x_{\mathrm{A}}}{2} \quad \text { and } \quad x_{\mathrm{A}} \leq \frac{(2-k) x_{\mathrm{D}}+k-1}{2 k-1} ; \\ 0, & \text { otherwise. }\end{cases}$

Proof. Setting $\Pi_{k}^{i}(0)>0$ is suboptimal and $\Pi_{k}^{i}(0)<0$ violates the individual rationality or participation constraint. Since $2 x_{i}+x_{j}-1$ may be negative it is optimal to have $p_{k}^{\mathrm{A}}\left(x_{\mathrm{A}}, x_{\mathrm{D}}\right)+$ $p_{k}^{\mathrm{A}}\left(x_{\mathrm{A}}, x_{\mathrm{D}}\right)<1$, a reserve price. Finally, the optimal allocation rule sets $p_{k}^{i}\left(x_{\mathrm{A}}, x_{\mathrm{D}}\right)=1$ only if the marginal revenue of bidder $i$ is larger than the one of bidder $j$.

The optimal auction is biased against the disadvantage bidder. He wins the good only if his signal is sufficiently higher than the one of her opponent. To see this consider the case in which both bidders receive the same signal $x \geq 1 / 3$. Bidder A wins with certainty as $k(3 x-1)>$ $3 x-1$ for any $k>1$. Thus the disadvantageous bidder must have a signal strictly higher than the one of the advantageous bidder to win. Nevertheless the optimal auction does not exclude the disadvantageous bidder from bidding. For a given signal $x_{\mathrm{D}}$, the signal by the advantageous bidder must be higher than $\left((2-k) x_{\mathrm{D}}+k-1\right) /(2 k-1)$ to win. 
At the optimal auction revenue to the seller becomes

$$
\begin{aligned}
R_{k}^{\mathrm{OP}}= & k \int_{0}^{1 / 3} \int_{\left(1-x_{\mathrm{D}}\right) / 2}^{1}\left(2 x_{\mathrm{A}}+x_{\mathrm{D}}-1\right) \mathrm{d} x_{\mathrm{A}} \mathrm{d} x_{\mathrm{D}} \\
& +k \int_{1 / 3}^{1} \int_{\left((2-k) x_{\mathrm{D}}+(k-1)\right) /(2 k-1)}^{1}\left(2 x_{\mathrm{A}}+x_{\mathrm{D}}-1\right) \mathrm{d} x_{\mathrm{A}} \mathrm{d} x_{\mathrm{D}} \\
& +\int_{1 / 2}^{1} \int_{0}^{\left((2-k) x_{\mathrm{D}}+(k-1)\right) /(2 k-1)}\left(2 x_{\mathrm{D}}+x_{\mathrm{A}}-1\right) \mathrm{d} x_{\mathrm{A}} \mathrm{d} x_{\mathrm{D}} \\
& +\int_{1 / 3}^{1 / 2} \int_{1-2 x_{\mathrm{D}}}^{\left((2-k) x_{\mathrm{D}}+(k-1)\right) /(2 k-1)}\left(2 x_{\mathrm{A}}-1\right) \mathrm{d} x_{\mathrm{A}} \mathrm{d} x_{\mathrm{D}} \\
= & \frac{1}{36}(2 k-1)^{-1}\left(42 k^{2}-19 k+3\right)
\end{aligned}
$$

\subsection{Revenue at the SPA}

When the auction is conducted as second-price, in equilibrium, the advantageous bidder plays a very aggressive strategy, whereas the disadvantageous plays very conservatively. In particular, the following strategies constitute an equilibrium for any $k>1, b_{k}^{\mathrm{A}}\left(x_{\mathrm{A}}\right)=x_{\mathrm{A}}+1$ and $b_{k}^{\mathrm{D}}\left(x_{\mathrm{D}}\right)=x_{\mathrm{D}}$ (see Bikhchandani, 1988).

The second-price auction generates an expected revenue equal to $1 / 2 .^{20}$

\subsection{Revenue comparison}

We have shown that the optimal auction does not exclude the disadvantageous bidder from bidding. This is also the case at the first-price auction, whereas it does not hold at the secondprice auction. Further, in both first-price and optimal, revenue increases with $k$, whereas it is independent of $k$ at the second-price auction. It is hence clear that the first-price is closer to the optimal than the second-price. To see the difference in expected revenues between the three mechanisms, table below provides the expected seller revenue at the optimal auction $\left(R^{\mathrm{OP}}\right)$, at a second-price auction $\left(R^{\mathrm{SP}}\right)$ and at the first-price auction $\left(R^{\mathrm{FP}}\right)$ for different values of $k^{21}$

\begin{tabular}{llll}
\hline$k=1$ & $k=1.5$ & $k=2$ & $k=3$ \\
$R^{\mathrm{SP}}=0.5$ & $R^{\mathrm{SP}}=0.5$ & $R^{\mathrm{SP}}=0.5$ & $R^{\mathrm{SP}}=0.5$ \\
$R^{\mathrm{FP}}=0.666$ & $R^{\mathrm{FP}}=0.837$ & $R^{\mathrm{FP}}=0.967$ & $R^{\mathrm{FP}}=1.5$ \\
$R^{\mathrm{OP}}=0.722$ & $R^{\mathrm{OP}}=0.958$ & $R^{\mathrm{OP}}=1.231$ & $R^{\mathrm{OP}}=1.8$ \\
\hline
\end{tabular}

The comparison for all values of $k$ is the content of Fig. 2. To obtain this figure, for the firstprice auction, we have numerically approximated the equilibrium correspondences, the bidding functions and the expected revenue (Fig. 2).22

\footnotetext{
20 There is a continuum of expected prices ranging from 0 to $1 / 2$. Nonetheless, the lower bound can be reached only if the disadvantageous bidder bids less than her individual rational bid.

21 As explained before, the choice of these values is not arbitrary. We have taken those for which the seller's expected revenue can be explicitly determined, without needing to rely on numerical calculations.

${ }^{22}$ When $1 \leq k<2$ we use the system of differential equations given by
} 


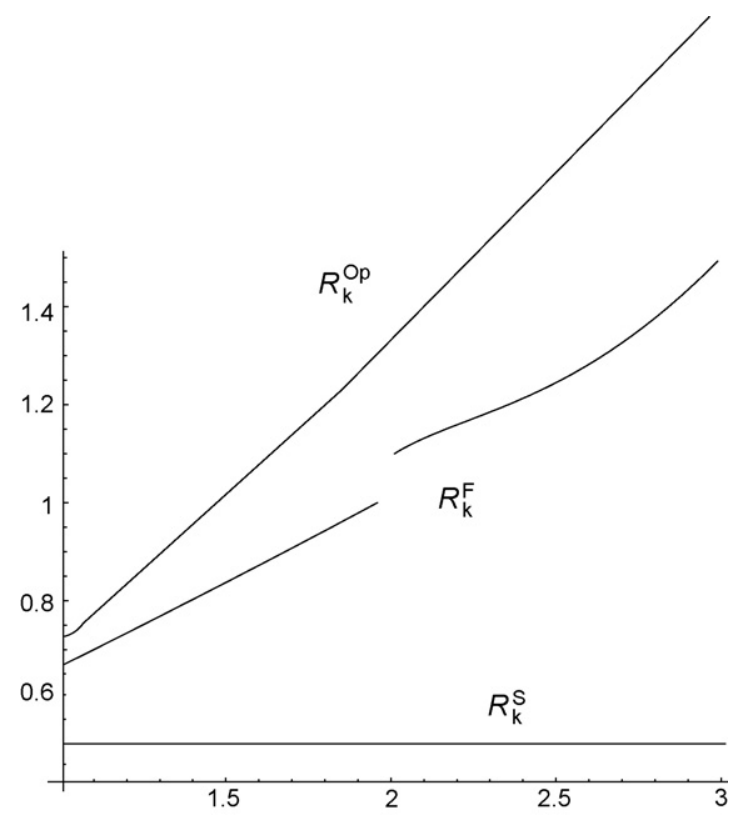

Fig. 2. The expected revenue as a function of $k$ for the three auctions: first $R_{k}^{\mathrm{F}}$, second $R_{k}^{\mathrm{S}}$ and optimal $R_{k}^{\mathrm{OP}}$.

\section{Robustness}

The model was based on a number of simplifying assumptions, and at this point we are interested in assessing the impact of relaxing them in our conclusions. In this section some alternative formulations are examined.

We have assumed here that $V=x_{\mathrm{A}}+x_{\mathrm{D}}$ which does not allow to see how different assumptions on partial derivatives (including cross partial derivatives) affect the results. ${ }^{23}$ To undertake this analysis we here take $V=g\left(x_{\mathrm{A}}+x_{\mathrm{D}}\right)$ for any continuous function $g$. Under this more general formulation the equilibrium bidding functions are the solutions to the system of differential

$$
\begin{aligned}
& \left(\Gamma_{k}\right)^{\prime}(x)=-b_{k}^{\mathrm{A}}(x) \phi_{k}^{\mathrm{D}}(x)-b_{k}^{\mathrm{D}}(x) \phi_{k}^{\mathrm{A}}(x) \\
& \left(\phi_{k}^{\mathrm{A}}\right)^{\prime}(x)=\frac{\left(\phi_{k}^{\mathrm{A}}(x)\right)^{2} k(2 k-1)+k x \phi_{k}^{\mathrm{A}}(x)}{(2-k) x^{2}+k x \phi_{k}^{\mathrm{A}}(x)} \\
& \left(\phi_{k}^{\mathrm{D}}\right)^{\prime}(x)=\frac{\left(\phi_{k}^{\mathrm{D}}(x)\right)^{2}(2-k)+k x \phi_{k}^{\mathrm{D}}(x)}{(2 k-1) x^{2}+k x \phi_{k}^{\mathrm{D}}(x)}
\end{aligned}
$$

with the initial conditions $\phi_{k}^{\mathrm{D}}(1)=\phi_{k}^{\mathrm{A}}(1)=1$ and $\Gamma_{k}(1)=0$. The first (auxiliary) equation is obtained by deriving

$$
\Gamma_{k}(x)=\int_{x}^{1} b_{k}^{\mathrm{A}}(s) \phi_{k}^{\mathrm{D}}(s) \mathrm{d} s+\int_{x}^{1} b_{k}^{\mathrm{D}}(s) \phi_{k}^{\mathrm{A}}(s) \mathrm{d} s
$$

with respect to $x$. Notice that $\Gamma_{k}(0)=R_{k}$, as it equals the sum of the bidders' expected payments. We numerically integrate (backwards) system above by using a Runge-Kutta method. Finally, to measure how the solutions change with $k$, we take a fine discrete grid of values of $k$. For $k \in[2,3)$ a similar method can be followed but taking for each $k$ the values of $s(k)$ and $r(k)$ that determine the initial conditions.

${ }^{23}$ We are very grateful to an anonymous referee who pointed this out. 
equations

$$
\begin{aligned}
& b_{k}^{\mathrm{A}}\left(x_{\mathrm{A}}\right)+\left(b_{k}^{\mathrm{A}}\right)^{\prime}\left(x_{\mathrm{A}}\right) x_{\mathrm{A}}=g\left(\phi_{k}^{\mathrm{D}}\left(x_{\mathrm{A}}\right)+x_{\mathrm{A}}\right), \\
& b_{k}^{\mathrm{D}}\left(x_{\mathrm{D}}\right)+\left(b_{k}^{\mathrm{D}}\right)^{\prime}\left(x_{\mathrm{D}}\right) x_{\mathrm{D}}=k g\left(\phi_{k}^{\mathrm{A}}\left(x_{\mathrm{D}}\right)+x_{\mathrm{D}}\right)
\end{aligned}
$$

with boundary conditions: $b_{k}^{\mathrm{A}}(0)=b_{k}^{\mathrm{D}}(0)=0$ and $b_{k}^{\mathrm{A}}(1)=b_{k}^{\mathrm{D}}(1)=m(k)$.

Using similar techniques to the ones employed in Section 3 it is easy to derive explicit expressions for the bidding functions in terms of the function $g$. They are given by:

$$
b_{k}^{\mathrm{A}}\left(x_{\mathrm{A}}\right)=\frac{k \int g(u) \mathrm{d} u}{\phi_{k}^{\mathrm{D}}\left(x_{\mathrm{A}}\right)+k x_{\mathrm{A}}},
$$

and

$$
b_{k}^{\mathrm{D}}\left(x_{\mathrm{D}}\right)=\frac{k \int g(z) \mathrm{d} z}{k \phi_{k}^{\mathrm{A}}\left(x_{\mathrm{D}}\right)+x_{\mathrm{D}}},
$$

where $u=x_{\mathrm{A}}+\phi_{k}^{\mathrm{D}}\left(x_{\mathrm{A}}\right)$, and $z=\phi_{k}^{\mathrm{A}}\left(x_{\mathrm{D}}\right)+x_{\mathrm{D}}$. For instance, when $g(y)=y^{s}$, the bidding functions become

$$
b_{k}^{\mathrm{A}}\left(x_{\mathrm{A}}\right)=\frac{k}{s+1} \frac{\left(\phi_{k}^{\mathrm{D}}\left(x_{\mathrm{A}}\right)+x_{\mathrm{A}}\right)^{s+1}}{\phi_{k}^{\mathrm{D}}\left(x_{\mathrm{A}}\right)+k x_{\mathrm{A}}},
$$

and

$$
b_{k}^{\mathrm{D}}\left(x_{\mathrm{D}}\right)=\frac{k}{s+1} \frac{\left(x_{\mathrm{D}}+\phi_{k}^{\mathrm{A}}\left(x_{\mathrm{D}}\right)\right)^{s+1}}{k \phi_{k}^{\mathrm{A}}\left(x_{\mathrm{D}}\right)+x_{\mathrm{D}}} .
$$

From the particular analytic structure of the above biding functions, it seems reasonable to claim that the results derived when $V=x_{\mathrm{A}}+x_{\mathrm{D}}$ will also hold if $V=\left(x_{\mathrm{A}}+x_{\mathrm{D}}\right)^{s}, s>0$. To asses this claim we have numerically computed the equilibrium for two particular functional forms $V=$ $\left(x_{\mathrm{A}}+x_{\mathrm{D}}\right)^{2}$ for which $\left(\partial^{2} V /\left(\partial x_{\mathrm{A}} \partial x_{\mathrm{D}}\right)\right)>0$, and $V=\left(x_{\mathrm{A}}+x_{\mathrm{D}}\right)^{1 / 2}$ for which $\left(\partial^{2} V /\left(\partial x_{\mathrm{A}} \partial x_{\mathrm{D}}\right)\right)<$ 0.

To do so, we have concentrated on the region of small asymmetries. Note that the range of $k$ in this region, $k \in[1, \tilde{k}]$, depends on the common-value functional form. If $V=\left(x_{\mathrm{A}}+x_{\mathrm{D}}\right)^{2}$ then $\tilde{k}$ is such that the valuation of player A- 0 , conditional upon winning over any type of player $\mathrm{D}$, is equal to the smallest possible valuation of player D-1, i.e., $\tilde{k}(1 / 2)^{2}=1$, which implies $\tilde{k}=4$. Similarly, if $V=\left(x_{\mathrm{A}}+x_{\mathrm{D}}\right)^{1 / 2}$ then $\tilde{k}=\sqrt{2}$ as $\tilde{k}(1 / 2)^{1 / 2}=1$. Once the range of $k$ values is determined, we derive and then numerically solve, the implicit equations that define the equilibrium correspondences. Finally, we substitute these expressions into (17) and (18) and we numerically compute the bidding functions in the three cases, i.e., $s=1 / 2,1,2$.

In Fig. 3(a) we show the equilibrium bidding functions for an advantageous bidders for $k=1.1$ in the three scenarios, while Fig. 3(b) shows the equilibrium bidding functions of the disadvantageous bidder. ${ }^{24}$ It stems from these figures that the explosive impact on auction outcomes, resulting from the tiniest asymmetry, in second-price auctions do not extend to the first-price auction format. Furthermore, the numerically computed bidding functions are close to the symmetric equilibrium bidding function in the three cases, confirming the robustness of Theorem 6 to changes in the common-value functional form.

\footnotetext{
${ }^{24}$ Note that $k=1.1$ lies in the range of small asymmetries in the three scenarios.
} 

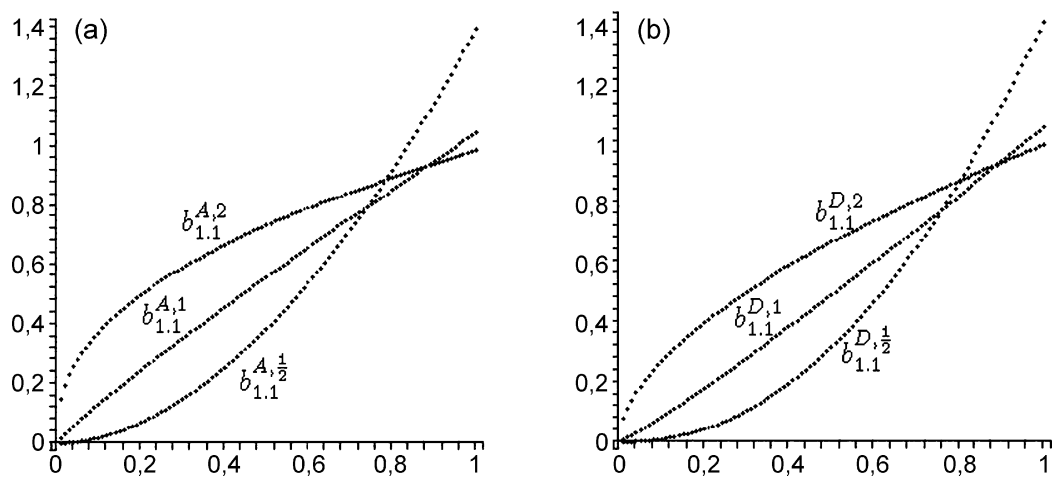

Fig. 3. The equilibrium biding functions for $s=1 / 2, s=1$ and $s=2$. (a) corresponds to bidder A while (b) corresponds to bidder $\mathrm{D}$.

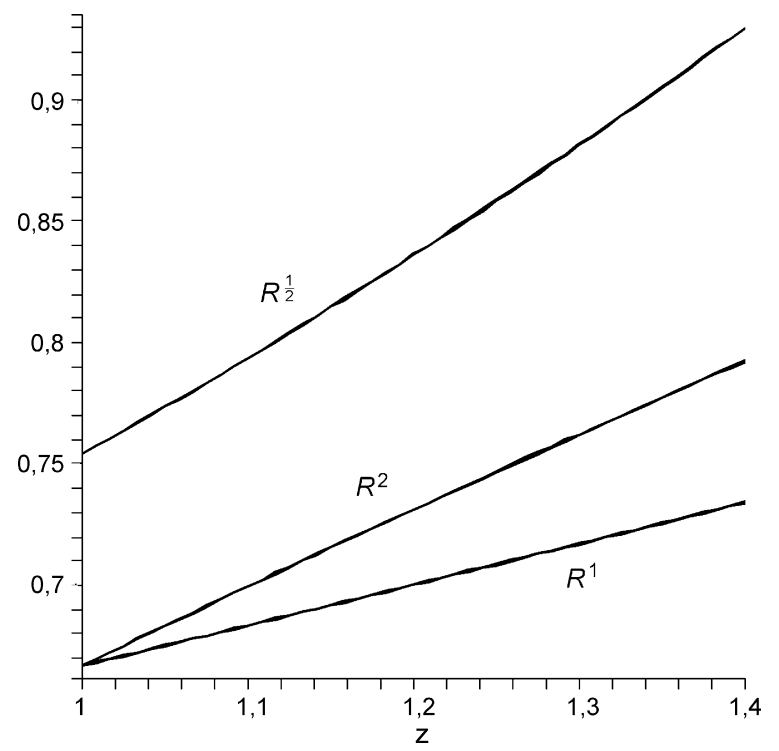

Fig. 4. The expected revenue as a function of $k$, for $s=1 / 2, s=1$ and $s=2$.

Finally, to further illustrate the behavior of the first-price auction format we here also provide a graphical representation of the seller's expected revenue in the three scenarios. Note that revenue is a monotone function of the degree of asymmetry, as illustrated in Fig. 4.

\section{Acknowledgements}

The authors have benefited from suggestions by an anonymous referee of this journal. Comments by David Pérez-Castrillo, Hugo A. Hopenhayn, Rafael Repullo and Michael Manove have substantially improve the paper. M. A. de Frutos acknowledges financial support from the Spanish Ministry of Education grant SEJ2004-01959. X. Jarque acknowledges financial support from the Spanish Ministry of Education grants SEC2003-00306 and MTM2005-02139, and the Catalan Government grant 2005SGR-00550. 


\section{Appendix A}

Proof of Lemma 1. First note that in a first-price auction the highest possible bid by each side must be the same. Otherwise, the player with the highest bid would be better off reducing his bid; he can still win with probability one while paying a lesser price. This fact provides the boundary condition: $b_{k}^{\mathrm{A}}(1)=b_{k}^{\mathrm{D}}(1)=m(k)$. We can hence define the bidding range as bids (or prices) below $m(k)$. In what follows we only consider the range of prices which are common to both players.

We first show that there cannot be simultaneous atoms at the same price. Assume that $p$ is an atom for player $i, i=\mathrm{A}, \mathrm{D}$, i.e., there is an interval of signals of player $i$ who are bidding the same price $p$. If this is the case, then all types of player $j$ who get strictly positive expected utility when bidding $p$, must prefer to bid slightly above the atom. Just note that this $\epsilon$-small deviation generates a positive surplus coming from the positive mass (atom) of $i$-players all bidding $p$. Hence, the only types of player $j$ that could prefer to bid $p$ rather than $p+\epsilon$ are those who get zero expected profits at $p$. But this can only happen for one type of player $j$ as, for each player, the value is strictly increasing in her signal.

We now use the result above to show, by contradiction, that there cannot be gaps. Assume that player $i$ has a gap at some interval within the common range, say $\left(p_{1}, p_{2}\right]$. Clearly, any player $j$ is better off bidding outside the gap. Further, unless player $i$ has an atom at the top of the gap, player $j$ would do better to lower the price at $p_{1}$ than to pay $p=p_{2}+\epsilon$. The reason is that by doing so she lowers the price she has to pay by a positive (away from 0 ) amount, while she only reduces her probability of winning by $\epsilon$. Consequently, $j$ must have a gap from $p_{1}$ or less to $\bar{p}>p_{2}$, contradicting that $i$ bids in equilibrium $p_{2}$. Consider then that $i$ has an atom at the top of her gap. Then, either $j$ also has an atom at $p_{2}$ which cannot happen in equilibrium as shown before, or $j$ bids $p_{2}$ with zero probability. But then $i$ should not bid $p_{2}$ with a positive probability. We can hence conclude that the bidding functions must be single-valued and continuous on the common range of prices.

We now show that if $k \in[1,2)$ then the common bidding range is the full range of prices. To do so we only need to show that the lowest bid is the same for both players, that is $b_{k}^{\mathrm{A}}(0)=b_{k}^{\mathrm{D}}(0)$. If $b_{k}^{\mathrm{A}}(0)<b_{k}^{\mathrm{D}}(0)$ then either bidder D-0 is losing money and she would hence do better decreasing her bid or bidder A-0 can do strictly better by increasing her bid. Consider now that $b_{k}^{\mathrm{A}}(0)>b_{k}^{\mathrm{D}}(0)$. By continuity of the equilibrium bidding functions there must exist $\tilde{x}>0$ such that $b_{k}^{\mathrm{A}}(0)=b_{k}^{\mathrm{D}}(\tilde{x})$, so that types $y, y \leq \tilde{x}$, of player D make zero profit. These types must find unprofitable to increase their bid or, otherwise, they would deviate. It must hence be the case that $b_{k}^{\mathrm{A}}(0) \geq \tilde{x}$. Further, since bidder A-0 cannot make negative profits, it must also be true that $b_{k}^{\mathrm{A}}(0) \leq k(\tilde{x} / 2)$. Notice that $k(\tilde{x} / 2) \geq b_{k}^{\mathrm{A}}(0) \geq \tilde{x}$ holds if and only if $k \geq 2$. Consequently, if $k<2$ then $b_{k}^{\mathrm{D}}(0)=b_{k}^{\mathrm{A}}(0)=0$, where the last equality follows straightforwardly.

To complete the proof we have to show that strategies are strictly increasing in the types so that there are no (individual) atoms. Observe that if $i$ has an atom in the common range then there is no $x_{j}$ that is willing to bid just after the atom ends; $x_{j}$ would prefer to bid just below (if the value conditional on winning the types within the atom is smaller that the price) or, just above (if the bid gets increased by an arbitrarily small amount whereas the probability of winning increases by the range of the atom). Consequently, since we have shown that there are no gaps, any atom must be at the bottom of the common bidding range. But this cannot be the case either. Note that if $k<2$ it would imply that a player with signal larger than 0 follows a weakly dominated strategy (bids zero rather than close to her positive signal). Since there can be no interval within the common bidding range at which a bidder bids with probability zero, players cannot choose mixed strategies. 
Lemma 14. The functions $b_{k}^{\mathrm{A}}\left(x_{\mathrm{A}}\right)$ and $b_{k}^{\mathrm{D}}\left(x_{\mathrm{D}}\right)$ are differentiable.

Proof. We prove the statement only for $b_{k}^{\mathrm{A}}\left(x_{\mathrm{A}}\right)$, the proof for $b_{k}^{\mathrm{D}}\left(x_{\mathrm{D}}\right)$ is similar and it is omitted. First we show that the function $x_{\mathrm{A}} b_{k}^{\mathrm{A}}\left(x_{\mathrm{A}}\right)$ is differentiable (so the expected utility is).

Since type $x_{\mathrm{D}}=\phi_{k}^{\mathrm{D}}\left(x_{\mathrm{A}}\right)$ must prefer to bid $b_{\mathrm{A}}\left(x_{\mathrm{A}}\right)$ rather than $b_{\mathrm{A}}\left(x_{\mathrm{A}}+\Delta x_{\mathrm{A}}\right)$, it must follow that

$$
\left[\phi_{k}^{\mathrm{D}}\left(x_{\mathrm{A}}\right)+\frac{x_{\mathrm{A}}}{2}-b_{k}^{\mathrm{A}}\left(x_{\mathrm{A}}\right)\right] x_{\mathrm{A}} \geq\left[\phi_{k}^{\mathrm{D}}\left(x_{\mathrm{A}}\right)+\frac{x_{\mathrm{A}}+\Delta x_{\mathrm{A}}}{2}-b_{k}^{\mathrm{A}}\left(x_{\mathrm{A}}+\Delta x_{\mathrm{A}}\right)\right]\left(x_{\mathrm{A}}+\Delta x_{\mathrm{A}}\right) .
$$

Rearranging we get

$$
\frac{b_{k}^{\mathrm{A}}\left(x_{\mathrm{A}}+\Delta x_{\mathrm{A}}\right)\left(x_{\mathrm{A}}+\Delta x_{\mathrm{A}}\right)-b_{k}^{\mathrm{A}}\left(x_{\mathrm{A}}\right) x_{\mathrm{A}}}{\Delta x_{\mathrm{A}}} \geq \phi_{k}^{\mathrm{D}}\left(x_{\mathrm{A}}\right)+x_{\mathrm{A}}+\frac{\Delta x_{\mathrm{A}}}{2},
$$

or, equivalently,

$$
\lim _{\Delta x_{\mathrm{A}} \rightarrow 0} \frac{b_{k}^{\mathrm{A}}\left(x_{\mathrm{A}}+\Delta x_{\mathrm{A}}\right)\left(x_{\mathrm{A}}+\Delta x_{\mathrm{A}}\right)-b_{k}^{\mathrm{A}}\left(x_{\mathrm{A}}\right) x_{\mathrm{A}}}{\Delta x_{\mathrm{A}}} \geq \phi_{k}^{\mathrm{D}}\left(x_{\mathrm{A}}\right)+x_{\mathrm{A}} .
$$

Since type $\phi_{k}^{\mathrm{D}}\left(x_{\mathrm{A}}+\Delta x_{\mathrm{A}}\right)$ must also prefer to bid $b_{k}^{\mathrm{A}}\left(x_{\mathrm{A}}+\Delta x_{\mathrm{A}}\right)$ than $b_{k}^{\mathrm{A}}\left(x_{\mathrm{A}}\right)$, similar computations to those used above yield the same equation but with the inequality reversed, and with lim sup instead of lim inf. From these two inequalities we conclude that the right derivative exists and is given by $\phi_{k}^{\mathrm{D}}\left(x_{\mathrm{A}}\right)+x_{\mathrm{A}}$. Using $x_{\mathrm{A}}-\Delta x_{\mathrm{A}}$ instead $x_{\mathrm{A}}+\Delta x_{\mathrm{A}}$ it is easily verified that the left derivative exists and is also given by $\phi_{k}^{\mathrm{D}}\left(x_{\mathrm{A}}\right)+x_{\mathrm{A}}$. Since the left and right derivative exist and coincide, the function $b_{k}^{\mathrm{A}}\left(x_{\mathrm{A}}\right) x_{\mathrm{A}}$ is differentiable, as desired.

Once we know the differentiability of $x_{\mathrm{A}} b_{k}^{\mathrm{A}}\left(x_{\mathrm{A}}\right)$ we want to show the differentiability of $b_{k}^{\mathrm{A}}\left(x_{\mathrm{A}}\right)$ for all $x_{\mathrm{A}} \in(0,1)$. If there were a point $z \in(0,1)$ for which the right and left hand side limits of the incremental quotients for $b_{k}^{\mathrm{A}}$ were not the same, this would imply, by taken the suitable limits, that $z \in(0,1)$ is a non differentiable point for $x_{\mathrm{A}} b_{k}^{\mathrm{A}}$ as well, a contradiction.

\section{References}

Avery, C., Kagel, J.H., 1997. Second-price auctions with asymmetric payoffs: an experimental investigation. Journal of Economics and Management Strategy 6, 573-603.

Ayres, I., Cramton, P., 1996. Deficit reduction through diversity: a case study of how affirmative action at the FCC increased auction competition. Stanford Law Review 48 (4), 761-815.

Bikhchandani, S., 1988. Reputation in repeated second-price auctions. Journal of Economic Theory 46, 97-119.

Binmore, K., Klemperer, P., 2002. The biggest auction ever: the sale of the British $3 \mathrm{G}$ telecom licenses. Economic Journal $112,74-96$.

Bulow, J., Klemperer, P., 2002. Prices and the winner's curse. Rand Journal of Economics 33, 1-21.

Bulow, J., Huang, M., Klemperer, P., 1999. Toeholds and takeovers. Journal of Political Economy 107, 427-454.

Caputo Silva, A., Kahn, C., 2001. Structural Analysis of Multiple-Unit Auctions: Recovering bidders valuations in auctions with dominant bidders. University of Illinois at Urbana-Champaign, Mimeo.

Che, Y.-K., Gale, I., 1998. Standard auctions with financially constrained bidders. Review of Economic Studies 65, 1-25.

Cramton, P., 2001. In: Martin, C., Majumdar, S., Vogelsang, I. (Eds.), Spectrum Auctions in Handbook of Telecommunications Economics. Elsevier Science B.V., Amsterdam.

Cramton, P., 1997. The FCC spectrum auctions: an early assessment. Journal of Economics and Management Strategy 6 (3), 431-495.

De Frutos, M.-A., Pechlivanos, L., 2006. Second-price common-value auctions under multidimensional uncertainty. Games and Economic Behavior 55, 43-72.

Goeree, J., Offerman, T., 2003. Competitive bidding in auctions with private and common values. The Economic Journal 113 (489), 598-613. 
Kagel, J.H., Levin, D., 2005. Almost common values auctions revisited. European Economic Review 49 (5), 1125-1136. Klemperer, P., 1998. Auctions with almost common values: the wallet game and its applications. European Economic Review 42, 757-769.

Klemperer, P., 2002. How (not) to run auctions: the European 3G telecom auctions. European Economic Review 46 (4-5), 829-845.

Maskin, E., Riley, J., 2000. Asymmetric auctions. Review of Economic Studies 67, 413-438.

Myerson, R., 1981. Optimal auctions design. Mathematics of Operation Research 61 (1), 55-73. 